\title{
Die Bedeutungsentwickelung des Wortes Roman.
}

Die grofse Zahl und ungemeine Beliebtheit der mit dem Worte Roman bezeichneten Werke haben schon früh zu zahlreichen Hypothesen über die Herkunft und ursprüngliche Bedeutung dieses Wortes Veranlassung gegeben. Eine Zusammenstellung dieser Erklärungsversuche aus früheren Jahrhunderten, die sich übrigens auf die sogenannten Ritterromane des Mittelalters beziehen, findet man z. B. bei Crescimbeni (Istoria della Volgar Poesia. Vol. I. Lib. V. p. 316): "Varie sono l'opinioni intorno al nome di Romanzo: imperocchè altri vogliono, che egli derivi dal Greco ' $P$ ó $\mu \eta$ che vuol dire fortezza; e significhi quello stesso che appo i Latini, Componimento Eroico: altri que sia originato dalla Cità di Rems di cui fu Arcivescovo il famoso Turpino, il quale nella sua favolosa Cronica amplissima materia apparecchiò a' Romanzatori: altri, che sì fatta voce importi lo stesso, che Romeo, e Pellegrino; e provvenga dall' uso de' Cavalieri antichi d'andar girando pel Mondo; onde erranti furono detti. Altri che da Romolo sia proceduta, per conto del ratto delle Sabine. Ed altri finalmente la vogliono nata dalla voce Ritmo e dicono, che altro non dovrebbe significare che canto di rime, ma l' uso l' intende per canzoni di Ceretani, e di Cantambanchi."

Alle diese Deutungen sind zwar ohne wissenschaftlichen Wert und können heutzutage nur noch als Curiosa angeführt werden, immerhin beweisen sie das rege Interesse, das man dieser Frage entgegenbrachte, ein Interesse, das auch heute noch nicht geschwunden ist. Zwar ist man sich darüber klar, dafs diese Benennung entstand, indem man das Wort Roman, ursprünglich nur die Bezeichnung einer Sprache, dann in übertragenem Sinne auch auf die in dieser Sprache geschriebenen Werke anwendete und schon Pasquier (Recherches de la France. Liv. VIII. Chap. I) hebt dies hervor: "et comme ainsi soit que le roman fut le langage courtisan de France, tous ceux qui s' amusoient d' escrire les faicts heroïques de nos chevaliers, premierement en vers, puis en prose, appellerent leurs œuvres romans, et non seulement ceux-là, mais aussi presque tous autres, comme nous voyons le Róman de la Rose, où il n' est discouru que de l' amour et de la philosophie"; im Einzelnen jedoch herrscht über diesen Gegenstand auch jetzt noch nicht genügende Klarheit, namentlich erübrigt es noch, den Uebergang des Wortes von der allgemeineren Bedeu- 
tung eines Werkes in romanischer Sprache zu anderen modifizierten Bedeutungen festzustellen; die bisher darüber geäusserten Ansichten aber sind mehr Vermutungen als Ergebnifse wirklich eingehender Untersuchung. Diese dunklen Punkte in der Geschichte des Wortes Roman aufzuklären soll in dem Folgenden versucht werden. In dieser Untersuchung wird es sich zunächst darum handeln, den Begriff des Wortes, sofern es Bezeichnung einer Sprache ist, festzustellen, sodann die Frage zu beantworten, wie man dazu kam, diesen Namen einer Sprache auf ein in ihr geschriebenes Werk anzuwenden, und schliefslich zu untersuchen, welche Modifikationen diese letztere Bedeutung des Wortes im Laufe der Zeit erlitten hat. Es sei gleich hier darauf hingewiesen, dafs unsere Untersuchung sich hauptsächlich mit der französischen Litteratur beschäftigen wird, denn eben in dieser und in engem Zusammenhange mit dem Gange derselben haben jene Wandlungen stattgefunden, durch welche das Wort schliefslich zu der ihm heute eigentümlichen Bedeutung gelangte. $\mathrm{Da}$ s auch die anderen romanischen Sprachen, soweit sie überhaupt in Betracht kommen, herangezogen werden, versteht sich von selbst.

"Romanisch" nennt man bekanntlich heute diejenigen Sprachen, welche eine Fortentwickelung sind der durch lokale Verhältnifse modifizierten römischen Volkssprache. Diese Benennung hat ihre Berechtigung nicht allein in dem gemeinsamen Ursprunge dieser Sprachen, sondern auch in dem Umstande, dafs sie alle, früher oder später, die eine mehr die andere minder oft, sich mit diesem Namen wirklich bezeichnet haben. Ueblicher war in diesem Falle für lingua romana das Substantiv: prov. romans, altfrz. romanz, span. port. romance, ital. romanzo (mlat. romancium), entstanden aus dem Adverb romanice.

Eine Abweichung hiervon ist nur zu constatieren beim Italienischen, indem zwar spätere italienische Litterarhistoriker das Altitalienische allerdings mit dem Namen "lingua romanza" oder "commune romanzo" bezeichnet haben, die altitalienischen Schriftsteller selbst jedoch ihre Sprache "volgar" nannten. So nennt sie noch Dante, und Boccaccio gebrauchte die Bezeichnung "volgar" latino. Die Sonderstellung, welche Italien in dieser Beziehung einnimmt, erscheint erklärlich, wenn wir bedenken, dafs wir uns hier an dem eigentlichen Heerde der lateinischen Sprache befinden, und dafs diese selbst sich im Altertum sehr selten "romana" nannte, wie sie denn auch im Mittelalter nur vereinzelt unter diesem Namen vorkommt. Den anderen romanischen Sprachen dagegen war diese Benennung geläufig und ist es zum Teil bis auf den heutigen Tag geblieben, so dem Rumonsch in Graubündten, dem Romęnie an der unteren Donau, dem Spanischen, das sich neben "lengua española" oder "castellana" auch "romance" nennt, sowie endlich dem Portugiesischen, wo romance nicht nur die eigene Landessprache bezeichnet, sondern auch in übertragenem Sinne auf die gemeinen Sprachen anderer Länder angewendet wird. In den beiden roma- 
nischem Sprachen Frankreichs ist die ursprüngliche Benennung "romams" am Ausgange des Mittelalters vollständig verdrängt worden durch die schon früher, wenn auch nicht allgemein üblichen $\mathrm{Be}$ zeichnungen "français" und "prouvençau". (Vgl. S. 489 f.).

D)as Romanische, als die Sprache der grofsen Masse des Volkes, trat nun schon in früher Zeit, lange bevor es zu einer schriftlichen Fixierung. desselben kam, in einen bewufsten Gegensatz zum Lateinischem, als der Sprache der Gesetzgebung, der Kirche und Wissenschaft ${ }_{n}$ dessen Kenntnis sich auf besondere Kreise beschränkte, und schon in einer lateinischen Ecloge, die Paschasius Ratbert $(\dagger 865)$ anführt, werden die lateinischen sowohl wie die romanischen Dichter aufgefordert, die Tugenden des Adalhard, Abtes von Corbie, eines Zeitgenossen Karls des Grolsen, zu feiern (s. Raynouard, Choix. II S. CXXXV). Dieser Gegensatz zwischen dem Romanischem und dem Lateinischen wird in den mittelalterlichen Texten an zahlreichen Stellen hervorgehoben und spielt in der Geschichte unseres Wortes eine wichtige Rolle. Schon in der Reimpredigt (ed.. Suchier) heilst es (Str. 1 27, 128):

“A la simple gent

Ai fait simplement

Un simple sarmun.

Nel fis as letrez,

Car il unt assez

Escriz e raisun.

Por icels enfanz

Le fis en romanz,

Qui ne sunt letré;

Car mielz entendrunt

La langue dunt sunt

Des enfance usé."

Oder um ein Beispiel aus dem Spanischen anzuführen:

"Quiero fer una prosa en roman paladino,

En qual suele el pueblo fablar a su vecino,

Car non so tan letrado por fer otro latino."

(Berceo, Vida de S. Domingo. de Silos. Str. 2).

An solchien Stellen, wo der Gegensatz zu der gelehrten Sprache, dem Latejinischen, hervorgehoben werden soll, wechselt unser Wort daher gern mit Ausdrücken wie "vulgar". So heisst es z. B. in dem provenzalischen Roman de Flamenca (ed. P. Meyer. V. 2108 ff.):

"Car si d' adiman ostas di

Avés aman, et en lati

Le premiers cas es adamas

E compo si d' ad e d' amas,

Mas lo vulgar a tan mermat

Cel ha que l'a en i tornat."

Obgleich nun beide Sprachen Frankreichs sich romans nannten, so scheint doch die Bedeutung des Wortes im Norden 
und im Süden nicht genau die gleiche gewesen zu sein. Jedenfalls hat man im Provenzalischen romans nicht gebraucht zur Bezeichnung jener höfischen Sprache der Troubadours, die sich vom I I. bis I3. Jahrhundert mit bemerkenswerter Stetigkeit erhielt, und von der Raimon Vidal sagt: "Per qu' ieu vos dic que totz hom qui vuella trobar ni entendre deu aver fort privada la parladura de lemosin." (Stengel, Die beiden ältest. prov. Gram. S. 7 I). Vielmehr scheint romans hier die allgemeinere Bedeutung bewahrt zu haben, während man jene Litteratursprache mit Vorliebe "dreg proenzal" oder ähnlich nannte. So entschuldigt sich Raimon Feraut, der aus der Grafschaft Nizza gebürtig war, wo man ebenfalls eine provenzalische Mundart sprach, in seinem Leben des heil. Honorat, dafs er nicht reines Provenzalisch schreibe, indem er sagt:

"E si deguns m'asauta

Mon romanz ni mos ditz,

Car non los ay escritz

En lo dreg proenzal,

Non m'o tengan a mal,

Car ma lengua non es

Del drech proensales." (Lex. Rom. I 573).

In Nordfrankreich hatte zwar auch, wie wir bereits gesehen haben, romanz zunächst jene allgemeinere Bedeutung, jedoch scheint man hier schon früh in engerem Sinne ein gutes Französisch darunter verstanden $\mathrm{zu}$ haben. In dieser doppelten Bedeutung stimmt es überein mit dem Worte français, das ja auch schon in früher Zeit in weiterem Sinne auf das ganze französische Sprachgebiet angewendet wurde, während es andererseits speciell auch die für besonders rein gehaltene Sprache des Herzogtụms Francien bezeichnete. Beide werden daher oft promiscue gebraucht. Einen Beleg findet jene engere Bedeutung des Wortes romanz durch Stellen wo die Kenntnis des letzteren als ein besonderer Vorzug hingestellt wird:

' $L$ ' amiraus des Arcois fu chevaliers vallans,

Et hardis et courtois et fiers et conquerrans;

Larges fu de douner plus que ne sui contans,

Vestus comme François et sot asés romans."

(Li Romans d'Alixandre, ed. H. Michelaut. S. 192, V. 13 ff.).

Dem entspricht genau der Gebrauch des Wortes français an Stellen wie dieser:

"Seiez debonere et cortois,

E sachez bien parler françois;

Kar molt est langage alosé

Et molt de. gentilhome amé."

(De la Rue, Essais sur les Bardes. I 28r).

An anderen Stellen wird das Romanz als eine besonders zu erlernende Sprache bezeichnet: 
"Car en s' enfance fu a escole mis,

Tant que il sot, et roman et latin."

(La Mort de Garin le Loh., ed. Du Méril. S. 105).

Auch Epitheta wie "bon", "gracieux" werden nicht selten dem Romanz gegeben:

"Moult volontiers me peneroie,

$\mathrm{Si}$ je m'en pooie entremettre

Qu'en bon romanz peusse mettre

Une estoire auques ancienne."

(Roman des Sept Sages, ed. Brunet et Montaiglon; am Eingang).

"Seigneurs, oyés chançon dont li ver sont plaisant,

Veritable et bien faite, d' un gracieux roumant."

(Léon Gautier, Les Epop. Franç. I 339).

Aus der folgenden Stelle wo von einem Eurupois (d. h. Bewohner der Gegend von Dourdan, dép. Seine et Oise) ausgesagt wird, dafs er gut romanisch spricht, könnte man vielleicht ebenfalls den Schlufs ziehen, dals man speciell die Sprache der Umgegend von Paris gern romanz genannt hätte:

\section{"L'autre fu Espeignos et l'autre fu Normans, \\ $\mathrm{Li}$ autre Eurupiei et parla bien roman."}

(Roman d'Alix., ed. Michelant. S. XIII).

Merkwürdig ist eine andere Stelle aus den Tournois de Chauvenci von Jacques Bretel (ed. Delmotte, V. 87 ff.), wo ein deutscher Ritter, der gebrochenes Französisch spricht, aufgefordert wird, an den Turnieren in. Chauvenci Teil zu nehmen, worauf er

\footnotetext{
“ . respondit faistisement:

Saurai-je bien parler romant?

La bon fransoise trestout sai .. "
}

Ein Schlufs auf die Bedeutung des Wortes wird sich jedoch aus dieser Stelle kaum ziehen lassen.

Wie schon bemerkt haben das Provenzalische und Französische die Benennung romans im Laufe der Zeit aufgegeben. Wann dies in dem ersteren geschah, ist schwierig anzugeben wegen des geringen Umfangs der provenzalischen Literatur in den späteren Jahrhunderten; jedenfalls war diese Bezeichnung im I4. Jahrhundert noch üblich (vgl. Bartsch, Chrest. Prov. 4. Aufl. S. 379, 30). Im Französischen gewinnt die Bezeichnung français bereits im 14. Jahrhundert entschieden die Oberhand. In der 2. Hälfte des 14. Jahrhunderts und im 15. Jahrh. werden die Fälle, wo das Französische romanz genannt wird, so selten, dals man geneigt ist, sie als Ausnahmen $\mathrm{zu}$ betrachten. Im $\mathbf{~}$ 5. Jahrh. ist also français die allein übliche Bezeichnung für die französische Sprache geworden. In den von Le Roux de Lincy (Livre des Proverbes Français. Bd. I. Bibliographie) angeführten Uebersetzungen lateinischer Sprichıörter ins Französische aus dem 15. Jahrh. wird z. B. stets français und nie romanz gebraucht. Die folgenden Stellen sind die einzigen 
aus der Zeit nach der Mitte des 14. Jahrhunderts, in denen mir romanz in dieser Bedeutung begegnet ist. Die letzte derselben ist aus dem Jahre 1445. Jean de Mandeville sagt in der Einleitung zu seiner Reisebeschreibung (geschr. 1356): "Et sachiez que j'eusse cest livres mis en latin, pour plus brievement deviser, mais pour ce que plusieurs entendent miex roumant que latin, je l'ay mis en roumant." Der Verfasser der Horloge de Sapience sagt am Schlusse derselben:

\author{
"De latin en roumanz donnee \\ Fut ceste histoire, celle annee \\ Que le myliaire couroit, \\ Qui proprement compter pourroit \\ MCCC IIIIXX et neuf, \\ En la ville de Chasteauneuf."
}

Jean Wauquelin sagt am Schlusse seiner Uebersetzung von Geoffrey von Monmouth's "Historia regum Britanniae": "Chi fine le histore des Bretons estraite du latin en rouman a la requeste de ... et fu translatee par ung bourgeois de Mons en Haynaut nommés Jehan Wauquelin en l'an de nostre Seigneur mille IIII cens XLV le XXV jour de juillet." (Ward, Catalogue of Romances in the British Museum. S. 253).

Wir werden also sagen, dafs das Wort romanz zur Bezeichnung des Französischen bereits im I4. Jahrhundert zurückzutreten begann, dafs es jedoch vereinzelt noch bis in die Mitte des 15. Jahrhunderts vorkommt. Dafs diese letzteren Fälle nur vereinzelt waren, dafür ist ein weiterer Beweis der Umstand, dafs man bereits im 16. Jahrh. dem "roman antique" das "français moderne" gegenüberzustellen pflegte. Dies thut z. B. Pierre Durant, welcher eine Prosaauflösung des Abenteuerromans Guillaume de Palerne anfertigte, in der Einleitung zu welcher er sagt: "Et ce considerant le langage qui estoit romant antique rimoyé en sorte non intelligible ne lisible à plusieurs favorisans à leur requeste come de chose tres convenable ay traduict et transferé le langage de cette histoire en langage moderne françois pour dे chacun qui lire le voudra estre plus intelligible." (Guill. de Palerne, ed. H. Michelant. S. XIX). Aehnlich ist die folgende Stelle aus Jean le Maire de Belges, wo dieser sich über den Alexandriner ausspricht: "Laquelle taille jadis avoit grand bruit en France, pour ce que les prouesses du roi Alexandre le Grand en sont escrites en anciens romans dont aucuns modernes ne tiennent compte aujourd'huy." (Fauchet, Recueil de l'Origine de la Langue et Poésie Franç., Paris i6ıo. S. 554).

Es bedarf kaum einer Erklärung, warum jene Benennung aufgegeben wurde. Romanz etc. war eben die gemeinsame Benennung mehrerer Sprachen, die zur Unterscheidung von einander besonderer Namen bedurften, welche dann naturgemäss die allein herrschenden wurden. So wählte man natürlich auch im Mittelalter die Bezeichnung romanz nicht, wenn verschiedene romanische Sprachen ein- 
ander gegenüber gestellt wurden, so z. B. wenn Raimon Vidal sagt: "La parladura francesca val mais et es plus avinenz a far romanz et pasturellas, mas cella de lemosin val mais per far vers et cansons et serventes." (Stengel, Die beid. ält. prov. Gr. S. 70).

Behielt man aber trotzdem das Wort romanz bei, so fügte man die nähere Bestimmung noch hinzu und sagte also "lemosi romans", "romance castellano" und dergl. Brunetto Latino giebt mit den folgenden Worten an, warum er in seinem Tresor (geschr. 1 269) die französische und nicht die italienische Sprache angewendet habe: "Et se aucuns demandoit por quoi cist livres est escriz en romans, selonc le langage des François, puisque nos somes Ytaliens, je diroie que ce est por II raisons: l'une, car nos somes en France; et l'autre porce que la parleure est plus delitable et plus commune à toutes gens." (Li Livres dou Tresor par Brunetto Latini, ed. Chabaille S. 3).

Zuweilen nimmt romanz auch die Bedeutung von Wort oder Rede im Allgemeinen an. So sagt die Schöne in dem Lai du Conseil (Lais inédits des XII et XIII siècles p. p. Fr. Michel S. 92), dals ein Ritter.um ihre Liebe geworben habe "par laiz, par escriz, par romanz" und Ferd. Wolf (Ueber die Lais. S. 5) möchte dies übersetzen: "in Liedern, Schreiben (Briefen) und Gesprächen". (s. S. 505). In entsprechender Weise gebrauchte man ja auch das Wort français, z. B.:

\section{"Si le proié par amistié \\ Que il m'en donnast la moistié. \\ Il dist que mon françois gastoie \\ Et que james n'en mengeroie."}

(Roman de Renart, ed. Méon I. V. 4083 ff.)

Die Bedeutung von Wort oder Rede überhaupt konnte dann in besonderen Fällen wieder zu beschränkteren Bedeutungen Anlals geben, wie in der folgenden Stelle aus Robert le Diable:

"Lor abaissierent lor roumans",

wo Ducange (Gloss. Med. et Inf. Lat. "Romancia") roumans übersetzt durch "murmure, plainte".

Die Bedeutung von romanz = "allgemein verständliche Sprache" gab Anlafs zu der im Altfranzösischen gleichsam sprichwörtlich gewordenen Ausdrucksweise "en romanz" und ähnlichen, was so viel heifst wie "klar, deutlich, ohne Umschweife" und unserem "auf gut deutsch" nahe kommt. Diese altfranzösische Ausdrucksweise, die selbstverständlich nur so lange üblich war als romanz die lebende Sprache bezeichnete, entspricht genau dem im Spanischen noch heute üblichen "en romance" oder auch "en buen romance", während das Italienische den analogen Ausdruck "in buon volgare" dafür hat. Um ein paar Beispiele anzuführen:

"En roumanz sans mot de latin

$\mathrm{Li}$ dist por quoi li rois le mande".

(R. de Renart. IV. V. 2484 f.) 
"Or vous dirai tout en rommanz".

(Baudouin de Condé. ed. Scheler. II. S. 50.)

"Et car laissiés aler dame Hersant

Dessi al chevalier a son talant:

Ele li dira ja de son romant".

(Aiol et Mirabel, ed. W. Förster. V. 2684 ff.)

In provenzalischen Texten finden wir daher romans zuweilen erzetzt durch Ausdrücke wie "plana paraula". So sagt der Übersetzer des Evangeliums Nicodemi:

"Car tornaray be veramen

Lo lati em plana paraula".

und Jaufre Rudel:

(Bartsch, Chrest. Prov. 4. Aufl. 380, 35 f.).

"Senes breu de pargamina

Tramet lo vers que chantam,

Plan et en lenga romana,

A'n Hugon Brun per Fillol". $\quad$ (Ib. 58, 4 ff.).

Im Deutschen finden wir das Wort Roman zur Bezeichnung einer Sprache z. B. bei Oswald von Wolkenstein (1367-1445), jedoch steht es nicht fest, ob es dort "römisch" oder "romanisch" bedeutet. Der Dichter sagt von sich (ed. Beda-Weber I 2,6):

"Franzoisch, Mörisch, Katlonisch und Kastilian, Teutsch, Latein, Windisch, Lampartisch, Reuschisch und Roman, Die zehen Sprach hab ich gepraucht."

Oswald brachte als Knabe den Sommer gewöhnlich mit seinen Eltern auf Schlofs Wolkenstein im Gredener Thal in Tyrol zu, wo eine romanische Mundart gesprochen wurde, die er sich rasch aneignete. Es ist, wenn auch nicht sicher, so doch nicht unwahrscheinlich, dafs er mit dem angeführten Roman diese Mundart meinte.

Es liegt nun in der Natur der Sache,' dafs man nur dann dazu kommen konnte, diese Bezeichnung einer Sprache auf ein in ihr geschriebenes Werk anzuwenden, wenn man dadurch einen gewissen Gegensatz $\mathrm{zu}$ anderen Sprachen oder besser $\mathrm{zu}$ Werken in anderer Sprache ausdrücken wollte. Ein solcher Gegensatz bestand nun zwischen dem Romanischen und dem Lateinischen im Mittelalter, ja er war schon lange bevor es zu einer schriftlichen Fixierung der romanischen Sprache kam, merklich hervorgetreten. Als daher die Litteratur in der Landessprache erwachte, wurde man sich dieses Gegensatzes bewulst und gab demselben Ausdruck, indem man die neuen, in der Vulgärsprache abgefa/sten Werke mit dem Namen dieser Sprache belegte. Es ist jedoch hierbei zu beachten, dafs dieser Gegensatz zwischen den beiden Sprachen allein wol kaum im Stande gewesen wäre, eine derartige, vielleicht einzig dastehende Bezeichnung hervorzurufen. Dazu war vielmehr ferner erforderlich, dals die Litteratur in der Landessprache bereits zu einiger Fixiertheit gelangt und sich ihrer Stellung neben der latei- 
nischen Litteratur bewufst geworden war. Dem entsprechend begegnet uns das Wort Roman im Französischen zur Bezeichnung eines Werkes in dieser Sprache, wie sich aus dem Folgenden ergeben wird, kaum vor der Mitte des 12 . Jahrhunderts.

Mit Vorliebe nannten sich nun diejenigen Werke Romane, welche entweder Übersetzungen oder Bearbeitungen lat. Texte waren, und bei ihnen lag ja auch diese Art der Bezeichnung besonders nahe, ja die ältesten sogenannten Romane beruhen in der That teils wörtlich, teils inhaltlich auf lateinischen Texten. Es liegt daher der Schlufs nahe, dals gerade sie es gewesen sind, welche zu dieser Bezeichnung den Anstols gegeben haben, indem sie jenen schon lange bestehenden Gegensatz nun auch wirklich aussprachen.

Das älteste Beispiel derselben dürte die Uebertragung der Sprüche Salomonis in Versen sein, welche in den vierziger Jahren des I 2. Jahrhunderts Samson de Nanteuil verfafste. Dieser sagt:

' $\mathrm{Ki}$ ben en volt estre enqueranz,

Entendet dunc a cest romanz

Que al loenge damne de

$E$ a s'enor at translaté

Samson de Nantuil."

(De la Rue, Essais sur les Bardes. II 133).

So giebt ferner Wace seinem Brut, für den die "Historia regum Britanniae" direkte Quelle ist, neben der specielleren Bezeichnung "Geste des Bretuns" auch die "allgemeinere Romanz", indem er am Schlusse sagt:

"Puis que Dex incarnassion

Prist por nostre redemption,

Mil et cent cinquante cinq ans,

Fist maistre Gasse cest romans."

Ebenso nennt Benoît de Sainte More sein auf dem Werke des Dares Phrygius 'De Excidio Troiae' beruhendes Epos widerholt Romanz, z. B.

"Or veuil je les romanz commencier.

Le latin suivrai à la lettre,

Nule autre riens n'i voudrai mettre."

Dieselbe Bezeichnung giebt Hue de Rotelande seinem Hypomedon (um II 85):

"Hue de Rotelande nous dit,

$\mathrm{Ky}$ ceste estorie nous descrit,

Ky de latin velt romanz fere

Ipomedon a tuz amanz

Mande saluz en cest romanz

Par cest Hue de Rotelande."

(Harry Ward, Catalogue of Romances. S. 743, 746).

Und Aimes de Varennes sagt von sich und seinem Florimond (geschr. II 88): 
"A ciaus qui sevent de clergie

Conte par ethymologie

Que por s'amie Vialine

Traist de grec l'istoire latine,

$E$ del latin fist le roumans

Aimes qui fu loiaus amans."

(P. Paris, Les Manuscrits Français III 43).

Die angeführten Beispiele mögen genügen, um diese Bedeutung des Wortes. für das 12. Jahrhundert festzustellen. Aber auch in den folgenden Jahrhunderten fehlt es keineswegs an Belegen für dieselbe und diese mehren sich in dem Grade, als überhaupt die Übersetzungslitteratur an Umfang und Bedeutung gewinnt, und sie verschwindet erst dann aus der französischen Litteratur, als man überhaupt aufhörte, die lebende Sprache mit dem Worte romanz zu bezeichnen. Das Festhalten an dieser Bedeutung ist aber darum so merkwürdig, weil andererseits dasselbe Wort schon früh zu engeren Bedeutungen gelangte, wie wir in dem Folgenden zeigen werden. Es dürfte daher wohl von Interesse sein, noch einige dieser späteren Belege zu hören:

"Si comme Dans Jehans nous devise

Qui en latin l'istore mist,

Et Herbers qui le romanz fist,

De latin en romanz le traist."

(Dolopathos, ed. Brunet et Montaiglon. V. 1844 ff.)

"En l'enor del bon duc Ferri

Qui tant dolcemant me norri,

Vuel un roman encomancier

Et del latin enromancier."

(Chronique abrégée des Calendre, in der Hist. Litt. de la France. XVIII 772).

Jean de Chastelet (um I 260 lebend) brachte die Disticha Catonis in französische Verse:

"Ce dit Jehans de Chastelet

Qui nous commence cest romanz

De Caton et de ses commens."

In dem Bestiaire des Gervaise (Romania I 426 ff.) heirst es (V. 35 f.):

" $\mathrm{Li}$ látins qui mult est plaisanz,

De illuec fu estraiz li romanz."

In demselben Bestiaire findet sich am Schlusse auch die Form "romain". Auch im Provenzalischen fehlt es nicht an späteren Belegen für diese Verwendung des Wortes. So nennt Raimon Feraut sein Leben des heil. Honorat (1300), da es auf einer lateinischen Quelle beruht "Romans". Bertran de Marseille sagt am Eingang seines Lebens der heil. Enimia (Lex. Rom. I 549):

"Trais aquest romans de lati" 
und der Uebersetzer des Evangeliums der Kindheit am Schlufs desselben:

"Aras son mons romans fenitz."

Die Uebersetzung des Titus Livius durch Pierre Berceure (geb. um I 300) führt den Titel: "C'est le Rommans de Titus Livius" (P. Paris, Les Manusc. Fr. I 32).

Der Frère Regnault de Louens, von dem wir eine Uebersetzung von Boetius' "De Consolatione Philosophiae" aus dem Jahre I 336 haben, sagt am Schlusse derselben:

"Si vous voulez savoir l'annee

Et la ville et la journee

Ou le frere parfist s'entente,

L'an mil CCC et six et trente

Le derrain jour de may prenez,

Si saurez quand a fin menez

Fut ce romant a Polligny."

I (de Bure, Catalogue de la Vallière. II 26I).

Das späteste Beispiel dieser Anwendung des Wortes Roman, welches mir begegnet ist, findet sich in einem Texte der ersten Hälfte des 15. Jahrhunderts. Jean Lefèvre übertrug um diese Zeit die Disticha Catonis in französische Verse und weist in den einleitenden Worten auf ältere Übertragungen desselben Gegenstandes hin:

"Si scey je bien que puis çà et ainçois

Que fusse nés, ils sont mis en françoys.

- Par maintes fois ay veu le rommans

Qui dist 'Seigneurs ains que je vous commans'.

Ce qui est dit ne vueil je plus remordre."

(Le Roux de Lincy, Livre des Prov. Fr. I. S. XCIX).

Nachdem so ein Mal der Anstols gegeben war, konnte es nun nicht ausbleiben, dafs auch andere, nicht auf lateinischen Texten beruhende Werke sich Romane nannten, indem damit nur angedeutet werden sollte, dafs sie eben in romanischer Sprache geschrieben waren. Diese allgemeine Bedeutung von 'Werk in romanischer Sprache" hat das Wort z. B. in der folgenden Stelle aus Wace's Rou (ed. Andresen. Teil III. V. 533 I f.):

"De romanz faire m'entremis,

Mult en escris e mult en fis."

So nennt auch Chrestien de Troies seine Dichtungen an zahlreichen Stellen Romane, z. B.:

"Del chevalier au lyeon fine

Crestiens son romanz ensi;

N'onques plus conter n'en oi,

$\mathrm{Ne}$ ja plus n'en orroiz conter,

S'an n'i vialt mançonge ajoster."

Und auch dieser Gebrauch des Wortes hat sich in den folgenden Jahrhunderten in der französischen Literatur erhalten. So beschlielst 
Walther von Metz seine Image du Monde (geschr. 1245) mit den Worten:

"Ci fenist l'Ymage dou Monde,

A Dieu comence, à Dieu prent fin.

En l'an de l'incarnation,

As rois, à l'apparicion

MCCXLV an

Fu premier parfeiz cist romanz",

(Hucher, Le Saint Graal. I 73).

Und in Froissart's Espinette Amoureuse heilst es:

" $\mathrm{Ne}$ vosisse que romans lire.

Especialment les trettiers

D'amours lisoie volontiers."

(Poésies de Froissart, ed. Scheler. I 96).

Wie wir im Verlaufe unserer Untersuchung sehen werden, tritt jedoch schon früh im Altfranzösischen die Tendenz zu Tage, diese Bezeichnung auf eine bestimmte Gattung von Werken in romanischer Sprache zu beschränken, und die Fälle, wo nicht zu dieser Gattung gehörige Werke sich Romane nennen, sind im Allgemeinen nicht zahlreich. Anders verhält sich dies im Provenzalischen, wo man es offenbar liebt, Werke der verschiedensten Art unter diesen allgemeinen Begriff zu subsumieren. So endigt, um nur einige Beispiele anzuführen, Folquet de Lunel sein Werk, das gegen die Mirsbräuche der Welt gerichtet ist und eine Aufzählung der Sünden aller Stände enthält, mit den Worten:

"En l'encarnassio fon fatz

De MCCLXXX

E catr' el romantz e retratz."

(s. Diez, Poesie der Troubadours. S. I19).

Daude de Prades schrieb ein Gedicht, in dem er Anweisungen gab um Vögel abzurichten. Auch er gab seinem Gedichte diese Benennung:

\section{"Segon so c'avia promes}

Mos romas del tot complitz es."

(Bartsch, Chrest. Prov. I82, 15 f.)

In dem Briefe des Matfre Ermengaud an seine Schwester heifst es am Schlufs:

"Aquest romans es acabat" (Lex. Rom. V 107).

Der Fierabras schliefst:

"Bon es d' aquest romans la fi e l'encontrada,

E'l mieg loc e per tot, qui be l'a escoutada."

(Lex. Rom. I 314).

Besonders beliebt ist im Altfranzösischen die Zusammenstellung von romanz und livre, wobei es wol am nächsten liegt, unter diesem ein Buch im Allgemeinen, unter jenem ein in romanischer Sprache geschriebenes zu verstehen, z. B.: 
"Ne porroit l'en les maus d'amer

Conter en rommant ne en livre."

(R. de la Rose, ed. Fr. Michel. V. 2618 f.).

Und in einem Verzeichnis v. J. I 387 heifst es: "un coffre de bois couvert de cuir, fermant d̀ clef, ferré et cloué ainsi qu'il appartient, pour mettre et porter en chariot les livres et romans de la royne" (bei Delisle, Le Cabinet des Manuscrits de la bibl. imp. I 49). Auch die Bezeichnung "livres roumans" findet sich mehrfach, z. B. aus d. J. I 404 "Inventoire des livres roumans de feu Monseigneur Philippe le Hardi" (Barrois, Bibl. Protypogr. S.I05. Ebenso S. I I I, I I 2). Von Mahaut, comtesse d'Artois et de Bourgogne wird uns berichtet, dafs sie i. J. 1323 "II romans et III autres livres" kaufte, die jedoch nicht einzeln aufgeführt sind. (Revue des Questions Historiques. Juli i 886. S. 236).

$\mathrm{Dafs}$ das Wort Roman jedoch bei der Bedeutung eines Werkes in romanischer Sprache nicht stehen geblieben, sondern zu derjenigen eines Buches überhaupt fortgeschritten ist, beweist die folgende Stelle aus einem Kataloge des Jahres I 4 I I: "Un gros rommant en françois, ou quel est contenu tout au long l'Histoire du Saint Graal, de Merlin, de la Nativité Lancelot et tous ses faitz, de la Table Ronde, du roy Artus .., (Gilles Mallet, Inventaire de l'anc. bibl. du Louvre. Paris I836. No. I1 22).

In geraden Gegensatz zu dieser Begriffserweiterung tritt nun jene merkwürdige und bedeutsame Wandlung, die das Wort Roman in seiner Bedeutung erlitt, die nämlich, dafs es von einem "Werke in romanischer Sprache" zu einer "Erzählung in romanischer Sprache" und schliefslich zu einer "Erzählung" überhaupt wurde. Um dieselbe zu begreifen, ist es nötig, einen Blick auf jene Werke zu werfen, die sich seit der Mitte des I2. Jahrhunderts als die ersten mit diesem Namen bezeichneten, und da ist es denn in die Augen fallend, dafs sie fast ausschliefslich der erzählenden Litteratur angehören. In den erzählenden Dichtungen liegt ja überhaupt der Schwerpunkt der altfranzösischen Litteratur und es lag daher nahe, dafs gerade sie, die so recht dem Nationalcharakter zusagten, diese volkstümliche Bezeichnung wählten, um so mehr als sie inhaltlich zum grofsen Teil auf lateinischen Texten beruhten. Vor Allem aber mufsten jene Dichtungen an sich bedeutend und populär genug sein, um durch ihren Einfluss eine Modifikation in der Bedeutung desjenigen Wortes bewirken zu können, mit dem sie sich vorzugsweise zu bezeichnen pflegten. Und dies waren sie in hohem Grade, repräsentieren sie doch zum guten Teil die höchste Blüte der mittelalterlichen Litteratur. Man denke nur an Werke wie Wace's Brut, dessen zahlreiche uns erhaltene Handschriften uns schon genügend seine Popularität beweisen, an den berühmten Roman de Troie des Benoît de Sainte More, an den Roman d'Alexandre des Lambert le Tort und Alexandre de Bernay, dessen Einfluls grols genug war, um der in ihm verwendeten Versart den Namen zu geben, oder ferner an die Werke des Chrestien de Troies, wohl 
des beliebtesten Erzählers des Mittelalters und der auch auf andere Dichter fruchtbar und folgenreich einwirkte, und endlich an die Fülle, der anderen erzählenden Dichtungen jener grofsen und bedeutsamen Zeit! Ein so gewichtiger Bedeutungswandel war natürlich nicht das Werk des Augenblicks, sondern dazu bedurfte es langer Jahre, in denen er sich nur allmählich vollzog, und das Wort wird notwendigerweise eine Zeit lang zwischen den beiden Bedeutungen hin und her schwanken. Diese Zeit des Schwankens ist im Wesentlichen die zweite Hälfte des I 2. Jahrhunderts und die Stellen, wo eine doppelte Auslegung möglich ist, sind daher in den Texten dieser Zeit zahlreich. Es wird von Interesse sein, dieses Schwanken in der Bedeutung des Wortes Roman an einigen Beispielen zu verdeutlichen. Dafs bei Beurteilung solcher Stellen die Entscheidung oft subjektivem Ermessen überlassen bleiben muls, versteht sich von selbst, und sie ist um so schwieriger zu treffen, als ja die allgemeinere Bedeutung von "Werk in romanischer Sprache" sich, wie wir gesehen haben, noch lange erhalten hat.

- Wace vergleicht im Rou (ed. Andresen. Teil III. V. I43 ff, I5 I ff.) sein Loos mit dem der Geschichtsschreiber in der guten alten Zeit mit den folgenden Worten:

\author{
"Mult soleient estre onuré \\ E mult preisié e mult amé \\ Cil ki les gestes escriveient \\ $\mathrm{E}$ ki les estoires faiseient. \\ Mais or puis ieo lunges penser, \\ Livres escrire e translater, \\ Faire rumanz e serventeis, \\ Tart truverai, tant seit curteis \\ Ki tant me duinst ...."
}

-Nach dem vorangehenden "translater" möchte man geneigt sein, unter "rumanz" aus dem Lateinischen ins Romanische übersetzte Werke überhaupt $\mathrm{zu}$ verstehen, andererseits spricht Wace in dem Vorhergehenden ausdrücklich von Werken erzählenden Inhalts und auch die Zusammenstellung "rumanz e serventeis" deutet bereits auf eine engere Bedeutung des ersteren hin.

Der Verfasser des Roman du Mont Saint Michel (geschrieben zwischen II54-1186), Guillaume de Saint Pair, schickt seinem eigentlichen Werke, in dem er die Gründung der Kirche auf jenem Berge und die dort geschehenen Wunder erzählt, einige einleitende Worte voran. In diesen sagt er, dafs Viele, die nach diesem Berge pilgern, sich mit Recht nach der Entstehungsgeschichte der dortigen Kirche $\mathrm{zu}$ erkundigen pflegen. Die ihnen auf ihr Befragen erzählten Geschichten seien aber oft falsch, er. habe es daher unternommen, diese Geschichte auf Grund authentischer Quellen in romanischer Sprache zu schreiben. Den Schlufs dieser Einleitung 
und den Übergang zu der eigentlichen Erzählung bilden dann die Worte :

"Celz vers ici or fenirai,

E mon romanz commencerai."

Man könnte auch hier an der allgemeineren Bedeutung festhalten mit Rücksicht darauf, dals das Werk angeblich auf einer lateinischen Quelle beruht, andererseits steht nach dem ganzen $\mathrm{Zu}$ sammenhange, in dem das Wort steht, auch der Zulassung jener engeren Bedeutung nichts im Wege.

Wenn Chrestien de Troies sagt (Cliges. V. 18 ff.):

"Ceste estoire trovons escrite,

Que conter vos vuel et retreire,

An un des livres de l'aumeire

Mon seignor saint Pere a Biauveiz.

De la fu li contes estreiz,

Don cest romanz fist Crestiiens",

so hat man zwischen beiden Redeutungen die Wahl: romanz kann hier sowohl ein Werk als auch eine Erzählung in romanischer Sprache bedeuten.

Zuweilen ist man geneigt, an verschiedenen Stellen ein und desselben Textes sich bald für die eine, bald für die andere $\mathrm{Be}-$ deutung zu entscheiden, so z. B. im Florimond:
"A ciaus qui sevent de clergie
Conte par ethymologie
Que por s' amie Vialine
Traist de grec l'istoire latine,
Et del latin fist le roumans
Aimes qui fu loiaus amans."

Hier ist die Bedeutung des Wortes wohl klar, in der folgenden Stelle aus demselben Gedichte dagegen könnte man unbedenklich eine "Erzählung in romanischer Sprache" darunter verstehen:

"Roumans ne estoire ne plait

As François se il ne l'ont fait."

(P. Paris, Les Manusc. Fr. III 43 und III 16).

Diese Bedeutung scheint das Wort auch in der folgenden Stelle aus dem Roman d'Athis et Porfilias des Alex. de Bernay (bei Ward, Catal. of Romances S. I 74) zu haben:

“ $D$ 'Atheine faut ici l'estoire

Que li escris temoign a voire.

Ici faut li romanz d'Atys,

De Porfilias ses amis

Et dou siege d'Atheine ansi

Se sont li Grezois departi."

Die angeführten Beispiele mögen genügen, um dieses Schwanken der Bedeutung des Wortes in der zweiten Hälfte des 1 2. Jahrh. zu verdeutlichen. Jedenfalls tritt schon in diesem Zeitraum die Hin- 
neigung $\mathrm{zu}$ jener modifizierten Bedeutung hervor, und am Ausgang des 1 2. oder Anfang des I3. Jahrh. begegnen uns bereits Stellen die diesen Übergang als einen vollzogenen erscheinen lassen, z. B.:

"Romans avés oï adiés

Les uns boins, les autres malvais

Hui mais porois romans oir

Qui a toute gent doit plasir.

N'est mie estrais de fausseté,

Anchois est fine verité."

(R. des Sept Sages, ed. Keller. V. 9 f., 245 ff.).

" $\mathrm{Li}$ uns viole, li autre conte romans"

(Girard de Vienne; bei Du Cange. "Romanus").

"Poi trouverés jouglierre qui de chesti vous chant,

Quar il en est moult poi qui sache le romans

Comme Garin fu pris a Monglane la grant."

(Gaufrey, ed. Guessard et Chabaille V. 269 ff.).

"Seignor, oï avez maint conte

Que maint conteres vos aconte,

Comment Paris ravi Helayne,

Les max qu'il en ot et la paine,

De Tristram qui la chievre fist,

Qui assez belement en dist

Et fables et chançons de geste,

Romanz du leu et de la beste

Maint autre conte par la terre."

(R. de Renart, ed. Méon I V. 1 ff.).

Von dieser Zeit ab begegnet das Wort Roman so allgemein in dieser Bedeutung von "Erzählung", dafs es überflüssig wäre, weitere Beispiele anzuführen; auch werden wir in unserer Untersuchung noch,oft genug Gelegenheit haben, solche Beispiele aus dieser und späterer Zeit anzuführen.

Wir haben somit den Zeitpunkt zu bestimmen gesucht, wo zaerst der Begriff der Erzählung in dem Worte enthalten war, dagegen mufs es dahingestellt bleiben, wie lange man den Begriff der Sprache noch damit verband, mit andern Worten: wann romanz von der Bedeutung "Erzählung in romanischer Sprache" zu der von "Erzählung" gelangte. Nur so viel lälst sich mit Bestimmtheit sagen, dafs nach dem I5. Jahrh. das Wort in der ersteren Bedeutung nicht mehr vorkommen konnte, wenigstens nicht sofern man dabei an die zeitgenössische Sprache dachte, und dafs man auch an die alte Sprache in diesem Falle nicht denken konnte, das bezeugt die weitere Geschichte des Wortes zur Genüge. Die Definition, welche Sylvius im 16. Jahrh. von dem Worte giebt "roman est historia gallico sermone conscripta" (bei Darmesteter et Hatzfeld, Le 16e Siècle en France. S. 187 Anm.) stölst das Gesagte nicht um, denn hier haben wir das Urteil eines Gelehrten, 
der grofsen Masse des Volkes dagegen war zu dieser Zeit ein Roman einfach eine Erzählung.

$\mathrm{Zu}$ den Werken erzählenden Inhalts gehören nun auch die Geschichtswerke, Chroniken, Annalen, Biographien und andere auf historischem Boden stehende Darstellungen, und auch diese haben sich schon früh mit Vorliebe Romane genannt, und zwar nicht nur diejenigen, welche angeblich oder wirklich auf lateinischen Quellen beruhten, sondern auch solche, bei denen dies nicht der Fall war. Schon in dem I 172 von Garnier de Pont Sainte-Maxence verfalsten Leben des heil. Thomas von Canterbury heifst es von diesem Werke selbst:

"Unc mes ne fu romanz mieldre fez ne trovet:

A Cantorbire fu et fet et amendés."

(P. Paris, Les Mss. Fr. III 82).

Dieselbe Bezeichnung trägt auch Joinville's Histoire de Saint Louis, ferner Guillaume Guiart's I 306 verfafste Branche des Royaus Lingnages, und unter dem I 2. Dez. I 381 wird uns berichtet von "LVI quayers que messire Jehan Froissart ... avoit fait escripre, faisans mencion de plusieurs et diverses batailles et besoignes en fait d'armes, faictes ou royaume de France le temps passé, lesquels LVI quayers de romans ou croniques le dit messire Jehan avoit envoié pour enluminer dे Guillaume de Bailly; enlumineur ..." (Journal de Jean le Fèvre, ms. français 5015, fol. 3. Angef. bei Delisle, Le Cabinet des Mss. I 55). Einen Beleg findet diese Verwendung des Wortes auch z. B. durch die folgende Angabe eines Katalogs aus d. J. I4II: “Un viel rommant en papier gros et court, en ryme, et parle des guerres d'Escoce et d'Angleterre." (Gilles Mallet, Inventaire de l'anc. bibl. du Louvre. Paris I836. No. I 120). Und noch im 16. Jahrh. spricht der Geschichtsschreiber Brantôme (I 540 bis 1614) in seinem Leben des Gonsalvo von Cordova von dem "Roman de Bayard" und meint damit die Lebensgeschichte des bekannten französischen Helden, deren eigentlicher Titel lautet: "Histoire du chevalier Bayard et de plusieurs choses advenues sous les règnes de Charles VIII, Louis XII et François I." (vgl. S. 517). Aber auch an anderen Zeugnissen fehlt es nicht für die Thatsache, dafs man hauptsächlich auch Geschichtswerke mit dem Namen Roman zu bezeichnen pflegte. Schon Thomas Tuscus sagt in seiner Chronik (13. Jahrh.): "Et ex hoc factum est, ut gesta in vulgari Gallico scripta romantia nominentur." (Pertz, Monum. Germ Hist. XXII 494, 38).

In ähnlicher Weise werden in einem Briefe König Johann's von Böhmen aus dem Anfang des 14. Jahrh. romancius und chronica zusammengestellt: "Nuper autem retulit nobis religiosus vir frater Petrus de Castro-Reginaldi ordinis fratrum praedicatorum, quod in magnum ipsius ordinis dedecus et contemptum facti sunt romancii, chronicae et moteti, in quibus continetur, quod clarae memoriae dominum et genitorem nostrum Imperatorem Henricum frater quidam Bernardus

Zeitschr. f. rom. Phil. $\mathbf{x}$. 
de Montepeluciano ordinis supradicti, administrando ei sacramentum Eucharistiae venenavit ..." (Du Cange, a. a. O. "Romancius"). Auch spätere Zeugnisse für diese Verwendung unseres Wortes sind vorhanden. So sagt de Pigna in seiner Abhandlung de' Romanzi: "Romanzi, secondo lo commune oppinione, in Francese detti erano gli Annali." (Ménage, Le Origini della Lingua Italiana, s. v." Romanzi").

Diese Bedeutung ist auch ins Italienische übergegangen, so wenn Pucci sagt:

"Poi cavalcar, come dice il romanzo,

Ed ebber presa la Terra di Moncia",

und unter dem Romanzo die Geschichte der Stadt Florenz des Giovanni Vilani versteht, die er in seinem Centiloquio in Verse gebracht hatte. (Tommaseo-Bellini, Dizionario della Lingua Italiana. "Romanzo").

Wenn nun aber auch das Wort Roman ganz im Allgemeinen zur Bezeichnung einer Erzählung gebraucht wurde, so trat doch eine weitere Modifikation dieser Bedeutung ein, indem man bald darunter eine speziell zum Sagen oder Lesen, nicht aber zum Singen bestimmte Geschichte verstand. Hier fällt es nun zunächst auf, dafs auch den "Chansons de geste", eine Benennung, in welcher ja bereits die Vortragsweise klar ausgedrückt ist, jene andere Benennung nicht fremd ist. Zwar haben sie dieselbe nicht so allgemein angenommen wie die höfischen Epen und andere Werke, denn sie hatten als die bedeutend älteren bereits eine ihnen eigentümliche Bezeichnung und nannten sich gewils als echte Produkte der Volkspoesie von jeher Chansons, aber einige von ihnen wenden doch beide Bezeichnungen: Romanz und Chanson neben einander an. So z. B. ist der Cyclus der Chansons de geste von Guillaume d'Orange in der Boulogner Handschrift überschrieben " Li Roumans de Guillaume d'Orange". Ähnlich heifst es im Elie de Saint Gille (ed. G. Raynaud. V. $275^{8}$ f.):

"Ichi faut li romanz de Julien li ber

Et d'Elye son fil qui tant pot endurer",

oder in Aiol et Mirabel (ed. W. Förster V. IO98I):

Et del romans Aiol est la rime finie.

Andere Beispiele sind:

"Son fils ot non Hugon de Saint Gille le grant,

Sire de Valvenise, la seignorie tenant,

Qui avec Godeffroy alla la mer passant,

Ainsi qu'avés oy recorder ou roumant."

(Parise la Duchesse, ed. Guessard et Larchey. S. XII).

"A Dieu vous comman je, ma canchon est finee.

De cest roumant est boine et la fin et l'entree,

Et enmi et partout, qui bien l'a escoutee;

$\mathrm{Ki}$ cest roumant escrist il ait boine duree."

(Fierabras, ed. Kröber et Servois. V. $6216 \mathrm{ff}$.). 
Wie man sieht, sind die Chansons, denen die angeführten Stellen entnommen sind, alle jüngeren Datums und werden gewöhnlich in den Anfang des 13. Jahrh. gesetzt (bei älteren Chansons wie dem Rolandslied kann diese Bezeichnung selbstverständlich überhaupt noch nicht vorkommen). An diesen und ähnlichen Stellen wird man wohl am besten thun, romanz mit "Werk in romanischer Sprache" zu übersetzen in Anbetracht der zahlreichen Stellen, in denen seit dem Anfange des 13. Jahrh. die Vortragsweise der Romane erwähnt wird und wo stets hur von einem conter, dire, lire, nie aber von einem chanter derselben die Rede ist. Das allmähliche Durchdringen dieser modifizierten Bedeutung ist zweifellos eine Folge davon, dafs sich von vorn herein hauptsächlich solche Werke diese Bezeichnung beilegten, die nicht zum Singen bestimmt waren, so die Reimchroniken, Biographien und ähnliche Werke, ferner die Erzeugnisse der späteren Kunstdichtung, die sich fast ausschliefslich so nannten, vor Allem aber auch erzählende Werke in Prosa, bei denen also ein Zweifel über ihre Vortragsweise gar nicht bestehen konnte (vgl. S. 5 I 3 f.). Zunächst einige Beispiele, wo von dem Erzählen oder Sagen eines Romanes die Rede ist:

" $\mathrm{Li}$ uns viole, li autre conte romans."

(Girard de Vienne; bei Du Cange. "Romanus").

"Cil vilain dont je vous commanz

A conter merveilleus romanz."

(R. de Renart, ed. Méon. II V. 15343 f.).

"Ausi com vos dirai avant,

S'oür volés icest roumant."

"Car vous arai contet et dit

(Ib. IV V. 139 f.).

Un roumant qui n'est mie briés."

(Barb. et Méon, Fabl. et Contes. IV 56).

Noch häufiger sind diejenigen Stellen, wo von dem Lesen eines Romanes gesprochen wird, z. B.:

\section{Et lisoit}

Une pucele devant lui

En un romans, ne sai de cui;

Et por le romans escoter

S'i estoit venue acoter

Une dame..."

(Li Romans dou Chev. au Lyon, ed. Holland V. 5356 ff.).

"Et si est grans

Et simple et avenans et coie

Et lisoit d'un romans de Troi e

K'ele avoit tantost commencié."

(Li Chev. as deus Esp., ed. W. Förster. V. 4270 ff.).

"Car. quant on ot un roumans lire, on entent les aventures aussi com s'eles fussent en present ici." (Bestiaire d'Amor des Richard de Furnival. Einleitung). 
"Empereor et roi et conte

Et duc et prince a cui l'en conte

Romanz divers por vous esbatre

De cels qni se seulent combatre

Çà. en arriers por sainte Yglise,

Quar me dites par quel servise

Vous cuidiez avoir paradis.

Cil le gaaignierent jadis

Dont vous oez ces romans lire."

(Oeuvr. de Rutebeuf, ed. Jubinal. Paris 1839. I 91).

Am schlagendsten beweisend für diese Bedeutung des Wortes sind aber diejenigen Stellen, wo es ausdrücklich Worten wie chanson, chant gegenübergestellt wird, denn bei ihnen kann kein Zweifel mehr bestehen, dafs diese Bedeutung einer nur gesagten oder gelesenen Erzählung auch wirklich in den Begriff des Wortes übergegangen war. Solche Beispiele sind die folgenden: In dem Roman Guillaume de Dol, den der Verfasser übrigens Romanz de la Rose nennt, und in den, wie in den Roman de la Violette kleine, zum Singen bestimmte Gedichte eingestreut sind, findet eine derartige ausdrückliche Gegenüberstellung von roman und chant statt. Es heifst dort:

“Et s'est fez par si grant delit

Que tuit cil s'en esjoüront

Qui chanter et lire l'orront,

Qu'il lor sera nouviaus toz jors.

Il conte d'armes et d'amors,

Et chante d'ambedeus ensamble.

S'est avis a chascun et samble

Que cil qui a fet les romans

Qu'il trovast toz les moz des chans;

Si afierent a ceuls del conte."

(Hist. Litt. de la Fr. XXII 826).

Anderswo sagt ein Trouvère von sich:

"Car ge sai de chançon de geste",

dann zählt er eine Reihe solcher, des komischen Effektes willen unter falschen Titeln, auf, und fährt fort:

"Mais de chanter n'ai ge or cure:

Ge sai des romanz d'aventure,

De cels de la reonde table

Qui sont a oür delitable."

(Oeuv. de Rutebeuf, ed. Jubinal. I 333 ff.). heirst :

Dem entspricht es, wenn es in dem Roman de l'Escoufle

"Mout lor sot bien chanter chançons

Et conter contes d'aventure."

(Hist. Litt. de la Fr. XXII 817). 
Nebenbei sei bemerkt, dafs Jubinal a. a. O. zu der obigen Stelle in einer Anmerkung sagt: "On voit que dès cette époque on distinguait les romans en romans de la table ronde, et romans d'aventure, c'est à dire probablement: romans de chevalerie, où les héros cherchaient des rencontres." Dieser Schlufs kann selbstverständlich aus obiger Stelle nicht gezogen werden.

Ein solcher Gegensatz ist wohl auch in der folgenden Stelle zwischen roman und chanson enthalten:

"S'Amors nel destraint et travaille,

Por neant en fet commençaille

En chanson, ne roman, ne livre."

(Li Romanz de la Poire, ed. Stehlich V. 344 ff.).

Auch im Provenzalischen finden sich Belege für diese Bedeutung des Wortes romans. Schon von Arnaud de Marueil wird gesagt :

"Arnautz e cantava be, e legia be romans."

(Lex. Rom. V 107).

Vor Allem hat hier Raimon Vidal an mehreren Stellen diese Bedeutung des Wortes hervorgehoben, so wenn er von sich sagt: "Senber, ieu soy us hom aclis
A joglaria de cantar,
E say romans dir e contar
E novas motas e salutz." (Choix V 343).

An einer andern Stelle sagt derselbe Dichter: "Per aqui mezeis deu gardar, si vol far un cantar o un romans, que diga rasons et paraulas continuadas et proprias et avinenz et que sos cantars o sos romans non sion de paraulas biaisas...", und bekannt ist der Ausspruch von ihm: "La parladura francesca val mais et es plus avinenz a far romanz e pasturellas, mais cella de lemosin val mais per far vers et cansons et serventes: et per totas las terras de nostre lengage son de maior autoritat li cantar de la lenga lemosina que de neguna autra parladura." (Die beid. ält. prov. Gr. ed. Stengel. S. 86 und 70). Die "vers, cansons et serventes" werden also als gesungene Gedichte bezeichnet und den Romanen gegenübergestellt. Dem entsprechend heifst es z. B. im Roman de Flamenca (ed. P. Meyer. V. 1714 ff.):

\section{"Chansons e lais, descortz e vers, \\ Serventes et autres cantars \\ Sa pia plus que nuls joglars."}

In der S. 491 citierten Stelle: "Par laiz, par escriz, par romanz" könnte man also auch, und das scheint mir das Wahrscheinlichere zu sein, romanz übersetzen durch "(gesagte) Erzählung" anstatt mit Wolf durch "Gespräch".

Auch im Spanischen bezeichnete man mit dem Worte romance, wenn es zur Bezeichnung einer Dichtungsgattung vor dem I5. Jahrh. vorkam (denn auch im Spanischen bedeutete es ursprünglich nur 
ein in der Vulgärsprache geschriebenes Werk) gewöhnlich ein mehr zum Sagen und Lesen, und nicht zum Singen bestimmtes episches Gedicht, im Unterschiede von den sogenannten Cantares de gestas. Diese spanischen Romances sind also nicht zu verwechseln mit den erst später auftretenden lyrisch-epischen und gesungenen Gedichten, die wir unter dem gleichen Namen kennen lernen werden (s. S. 521 f.). Dafs man unter den ersteren schon kunstmäfsiger abgefalste Erzählungen verstand, beweist die folgende Stelle aus dem Gedichte Appolonio (bei Du Méril, Poésies Popul. Lat. du Moyen Age S. 295):

"En el nombre de Dios e de santa Maria,

$\mathrm{Si}$ ellos me guiasen estudiar queria

Componer un romance de nueva maestria",

wo aus der letzten Zeile deutlich hervorgeht, dafs der Dichter nicht beabsichtigte, eine volkstümliche Dichtung zu schreiben. Auch Epitheta wie "fermoso, bien rimado" und ähnliche deuten darauf hin. Für die Vortragsweise charakteristisch ist eine andere Stelle aus demselben Gedichte (Copla 428), wo Tarsiana als Joglaresa auftritt, und, nachdem sie viele Lieder mit Begleitung der Viola auf dem Markte für Lohn gesungen hat, ihre eigene Geschichte in einer Romanze zu erzählen beginnt:

"Quando con su viola huvo bien solazado, A sabor de los pueblos huvo asaz cantado, Tornóles á rezar un romanze bien rimado

De la su razon misma por do avia pasado."

(Vgl. hierüber Ferd. Wolf, Über die Romanzenpoesie der Spanier. In den Wiener Jahrbüchern d. Literat. CXVII 82 ff.). Ob übrigens im Spanischen diese an die Vortragsweise anknüpfende Bedeutung des Wortes eine so ausgesprochene war wie im Französischen, scheint fraglich in Anbetracht der späteren Bedeutung, die es in dieser Sprache annahm.

Ganz in derselben Weise wie romanz wird auch das Wort dit im Französischen Worten wie chant etc. gegenübergestellt, so z. B. in der Chantefable Aucassin et Nicolete (ed. Suchier. 1, $8 \mathrm{f}$.):

"Dox est li cans, biax li dis

Et cortois et bien asis",

oder im Roman de la Violette (ed. Michel. S. 4):

“Et s'est li contes biaus et gens

Que je vous voel dire et conter,

Quar on i puet lire et chanter,

Et si est si bien acordanz

Li cans au dit. Les entendans

En trai a garant que di voir."

Ferd. Wolf, (Über die Lais. S. 252 ff.) hat eingehender über die mit dem Namen Dit (oder Ditié) bezeichneten Gedichte gehandelt und diese Vortragsweise als das Charakteristische derselben hin- 
gestellt auf Grund zahlreicher Belegstellen, die sich leicht vermehren liefsen. Das Resultat seiner Untersuchung fafst er in die Worte zusammen (a. a. O. S. 258): "Wenn daher weder in dem Inhalte noch in der Form allein das charakteristische Merkmal der doch durch einen eigenen Namen, Dits oder Ditiés, bezeichneten Dichtungsgattung zu suchen ist, so wird es sich wohl nur in der Vortragsweise finden, die eben durch den Namen schon hinlänglich gekennzeichnet wird, und welche dann zu der oben erwähnten didaktischen Tendenz und historischen Färbung des Inhalts, und zu den strophenlosen, oder zwar strophischen, aber zum Gesange minder tauglichen Formen auch die passendste war." Es sei uns gestattet einige weitere Bemerkungen über diese Dichtungsgattung hinżuzufügen.

Aus der Grundbedeutung des Wortes von Gesagtem ergiebt sich zunächst ohne Schwierigkeit diejenige von Erzählung, und es wird daher besonders gern mit Worten wie conte zusammengestellt, z. B.:

"Ge sai contes, ge sai flabeax,

Ge sai conter beax diz noveax."

(Oeuv, de Rutebeuf, ed. Jubinal I 339).

" Je vous ai mainz moz fabloiez,

Et diz et contes rimoiez."

(Hist. Litt. de la Fr. XXIII 262).

"On tient le menestrel a sage,

Qui met en trover son usage,

De fere biaus dis et biaus contes

C'on dit devant dus, devant contes."

(Barb-Méon, Fabl. et Contes. III 398, 3 ff.).

"Jamais ne bel dit, ne bel conte,

N'iert mais de li a cort retrait.

(Ib. III 4I9, 340 f.) etc.

Werden romanz und dit zusammengestellt, so scheint man unter jenem eine umfangreichere, unter diesem eine kürzere Erzählung verstanden zu haben. So lauten die Anfangsverse des Roman des Sept Sages (ed. Keller):

"Plaist vous oïr bons dis et biaus

Qui sont d'auctorité nouviaus?

Et sample sont tuit veritable,

N'est mie mençoigne ne fable."

Unter diesen Dits sind zweifellos die einzelnen Erzählungen der Dichtung zu verstehen. Dagegen wird weiter unten das gesamte Werk mit dem Namen Roman bezeichnet (V. 245 ff.):

"Hui mais porois romanz oïr

Qui a toute gent doit plasir,

N'est mie estrais de fausseté,

Anchois est fine verité." 
An zahlreichen Stellen berufen sich die Dits darauf, dafs sie nur Wahres berichten wollen (wie sie ja auch nicht selten an historische Ereignisse oder Personen anknüpfen), und treten daher besonders in einen Gegensatz zu den Fablels, deren erfundene Erzählungen so in Mifskredit gekommen waren, dafs z. B. ein Fableldichter selbst ein solches mit den Worten beginnt:

\section{"Se fabliaus puet veritez estre, \\ Dont avint il, ce dist mon mestre, \\ C'uns vilains a Bailleul manoit..."}

(Jubinal, Nouv. Rec. I 31 2).

Eine solche Gegenüberstellung von dit und fablel findet z. B. statt in dem Dit du Chancelier Philippe des Henri d'Andely, von welchem der Verfasser sagt:

"Por ce qu'il est de verité

Ne l'apele mie fablel;

Ne l'ai pas escrit en tablel,

Ains l'ai escrit en parchemin

\section{Cest dit fit Henris d'Andely."}

So nennt auch Guillaume de Machaut eine seiner Dichtungen "Le Livre du Voir Dit", um das darin Erzählte als wirklich Geschehenes hinzustellen. Die folgende Stelle aus dem schon genannten Dit du Chancelier Philippe ist darum interessant, weil man aus ihr ersehen kann, dals es den Dichtern solcher Dits hauptsächlich um Popularität und möglichst weite Verbreitung ihrer Gedichte $z u$ thun_war:

"Par bois, par plains et par chemin,

Par bois, par chasteals, par citez

Vodra qu'il soit bien recitez."

Die grofse Masse des Volkes nun, an welche doch die Dits hauptsächlich gerichtet waren, verlangte keine Kunstwerke, und eine grofse Anzahl derselben ist in der That, inhaltlich wie stilistisch recht unbedeutend, sondern sie war zufrieden, wenn ihr nur etwas Neues, und war es auch noch so unbedeutend, aufgetischt wurde. Hieraus erklärt es sich wohl, warum diese Dits sich mit Vorliebe "neue Dits" nennen, ja das Wort nouvel ist, neben bel, gleichsam ein stehendes Beiwort dieser Gedichte geworden.

Hierfür einige Beispiele:

"Ge sai contes, ge sai flabeax,

Ge sai conter beax diz noveax,

Rotruenges viez et noveles

Et sirventois et pastoreles."

(Oeuv, de Rutebeuf, ed. Jubinal I 339).

"Un noviau dit ici nous trueve

Guillaume de la Villenueve."

(bei Barbazan. II 276). 
"En l'ouneur de Marcheandie

M'est pris talent que je vous die,

Se il vous plaist, un nouvel dit." (Ib. II 30I).

"De dire contes et fabliaus

Et de trover biaus dis noviaus

Se soloient ja entremetre

Et grant peine $i$ soloient metre

Cil qui seulent dire et conter."

(Jubinal, Jongleurs et Trouv. S. 128).

Auch "merveilleus" nennen sich die Dits zuweilen:

"Seignor, mult me merveil que cist siecles devient,

Et de ceste merveille trop souvent me souvient

Si qu'en moi merveillant, a force me convient

Faire un dit merveilleus qui de merveille vient."

(Rutebeuf ed. Jubinal. I 175).

Hiermit ist sehr wohl vereinbar, dafs ein grolser Teil der so bezeichneten Gedichte Gelegenheitsgedichte sind, so das schon erwähnte Dit auf den Tod des Kanzlers Philipp und viele andere. So besitzen wir ein dieser Gattung zugehöriges Gedicht des Godefroy de Paris: "De la Comète et de l'Eclipse, et de la Lune et du Souleil", in welchem der Verfasser von den Kometen und Sonnenfinsternissen berichtet, die sich in den Jahren 1314 und 1315 beim Tode Philipps des Schönen und seines Sohnes Ludwig zeigten. Das Gedicht beginnt mit den für die Gattung überhaupt bezeichnenden Worten:

"Chascun me demande nouvelles

Et j'en sai, mes ce sont de celles

Dont ou monde court la maiere."

(P. Paris, Les Mss. Fr. I 334).

Die didaktische Tendenz der Dits wird an zahlreichen Stellen ausgesprochen, z. B.:

"D'un dit fere me renovel

Où talent m'est pris que repraigne

Le monde ..." (Jubinal, Nouv. Rec. II 58).

"Dont pour endoctriner cest roy

Un dit fu fait de tele loy."

(Ib. II 4I7) etc.

Wie ausgesprochen diese didaktische Tendenz war, dafür ist ein interessanter Beleg das Avisemens pour le roy Loys des schon erwähnten Godefroy de Paris. Der Dichter setzt dem König, Ludwig X., zunächst die Pflichten eines Regenten auseinander. "Après cette exposition, le poète blâme amèrement et longuement certains auteur de "dits" prétendus moraux, mais qui, dans le fond, renfermaient des invectives contre l'église et non des enseignements salutaires." (P. Paris, Mss. Fr. I 326).

Wenn oben das Sagen als die charakteristische Eigenschaft der Dits hingestellt wurde, so darf doch nicht unerwähnt bleiben, 
dafs auch Stellen vorkommen, wo von einem musikalischen Vortrag derselben gesprochen wird, z. B.:

"La sont li jogleor, cantent lais, notent dis."

"E jogleor i cantent et lais et sons et dis."

(R. de la Violette, ed. Fr. Michel. S. I53 Anm.).

"Si chantons chançons noveles,

Biaus dis, beles notes ...."

(Bartsch, Romanzen und Pastour. S. XIV).

Auch prosaische Werke erzählenden Inhalts nennen sich übrigens, wenn auch verhältnismälsig selten, Dits oder Ditiés, so z. B. die von de Wailly unter dem Titel "Récits d'un Ménestrel de Reims" herausgegebene Chronik (Ib. S. 27).

Die Dits erinnern somit in vieler Beziehung an die deutschen "Sprüche"; unter welchem Namen wir aus dem I 5. Jahrh. ebenfalls erzählende Gedichte von den Nürnberger Dichtern Folz und Rosenblüt besitzen (s. Wackernagel, Geschichte der deutschen Literat. S. 198). Auch sie wurden vorzugsweise gesagt, und nicht gesungen, und auch von ihnen wird zuweilen, entgegen der Regel, von einem musikalischen Vortrag gesprochen (s. Scherer, Deutsche Stud. I 33 I), und sie gleichen sich endlich auch in der ihnen eigentümlichen didaktischen Tendenz. - Alle die angeführten Merkmale treffen zwar im Grofsen und Ganzen für die mit dem Worte dit bezeichneten Dichtungen $\mathrm{zu}$, im Einzelnen jedoch finden manche Abweichungen statt und eine feste Abgrenzung wie bei anderen Dichtungen ist daher kaum möglich. Eben darum nicht, weil der Begriff dieses Wortes ein zu weiter war und man z. B. darunter auch ein Gedicht im Allgemeinen verstand. Daher denn auch häufige Schwankungen in der Bezeichnung. So wird, um nur ein Beispiel anzuführen, die Erzählung vom Pellican in einer Handschrift "Li Lais dou Pellican" genannt, während es in einer andern Handschrift unter dem Titel "Le Dit dou Pelican" aufgeführt wird (s. Ferd. Wolf, Über die Lais S. 69). Auch zeitlich sind die Dits von einander verschieden. Einige der älteren sind blofse Nomenklaturen, wie die Dits des Crieries de Paris, des Moustiers de Paris und ähnliche, während man später diese Bezeichnung auch auf Bearbeitungen älterer Romane, z. B. le Dit de Guillaume d'Angleterre, sowie auf grölsere allegorische Dichtungen, wie le Dit de la Panthère, anwendete. Heute ist diese Verwendung des. Wortes aufser Gebrauch gekommen.

Kehren wir zum Worte Roman zurück. Wir haben dasselbe in seiner Geschichte bis dahin begleitet, wo es zu der Bedeutung einer gesagten oder gelesenen Erzählung gelangt war. Es bleibt nun zunächst die weitere Frage zu beantworten, ob man es vielleicht nur auf eine in Versen, oder aber in Prosa abgefafste Erzählung anwendete, oder ob ein solcher Unterschied nicht bestand und man Werke beiderlei Art mit dem gleichen Worte bezeichnete. Bevor wir dies untersuchen, ist es nötig einen kurzen Blick zu 
werfen auf das Verhältnis von Poesie und Prosa in der französischen Litteratur des Mittelalters überhaupt. Das 12. und I3. Jahrh. waren die Blütezeit der mittelalterlichen Dichtkunst gewesen, in ihr hatte das Epos die höchste Stufe seiner Entwickelung erreicht. Schon gegen Ende dieses Zeitraums jedoch zeigte das erwachende Gefallen am Allegorischen, wie es im Roman von der Rose vor Allem zum Ausdruck kam, dals Lust und Trieb zur Poesie zwar noch vorhanden waren, dafs dagegen die poetische Zeugungskraft selbst zu ermatten begann. Die Allegorie bildete nur den Übergang von der Poesie zu der diese verdrängenden Prosa. Zwar war schon immer die Prosa neben der Poesie hergegangen, aber erst im 14. Jahrh. tritt sie mehr und mehr in den Vordergrund, um dann im 15. Jahrh. die streng poetische Form fast ganz zu verdrängen. Das Interesse an den behandelten Stoffen dagegen war noch nicht geschwunden, und so treten uns denn hauptsächlich Umformungen der alten Epen zu prosaischen Ritterromanen entgegen, die dann die Lieblingslektüre des französischen Publikums bis um die Mitte des 16. Jahrh. gebildet und sich zum Teil als Volksbücher im wahrsten Sinne des Wortes bis auf den heutigen Tag erhalten haben. Interessant ist es übrigens die Gründe zu hören, welche die Verfasser selbst anführen dafür, dafs sie die prosaische Form wählen, und da schützen sie denn meist vor, dafs die gereimten Erzählungen als solche notwendig Unwahrheiten enthalten. So erklärt der Verfasser einer späteren französischen Bearbeitung der Historia Troiana des Guido delle Colonne: "Et de gregoys (?) je l'ay translatee en françois, non pas par ryme ne par vers, ou il convient par force mensonges maintes mectre; comme font ces menestiers qui de leur langue font mainteffoys de quoy ilz font souvent leur prouffit et aultruy domaige." (Harry Ward, Catal. of Rom. S. 58).

An andern Stellen kommen die angeführten Gründe der Wahrheit näher und charakterisieren dann das abnehmende Verständnis für die Poesie in jener Zeit, z. B.: "Ce livre fut fait ... aussi comme pour declairer aucunes choses que la ryme contient qui semblent estre obscures et estranges de premiere face. Et pour ce fut il fait en prose pour ce que prose est plus clere a entendre par raison que n'est ryme." (P. Paris, Les Mss. Fr. I 280).

Die Einen haben nun die Ansicht aufgestellt, dafs man unter Romanen besonders Erzählungen in Prosa verstanden habe, namentlich im Anschlurs an die oft besprochene Stelle aus Dante's Purgat. XXVI I 8 f. über den Troubadour Arnaut Daniel:

\section{"Versi d'amore e prose di romanzi Soverchio tutti"}

(Vgl. dazu Diez, Poesie der Troub. S. 208 f. Ferd.Wolf, Über die Lais S. 305, G. Paris, Romania X 478). Und noch in neuester Zeit ist diese Ansicht von Einigen vertreten worden, wie die folgende Stelle 
beweist: "C'étaient surtout des récits d'aventures guerrières et merveilleuses que les trouvères et les jongleurs français avaient fait entendre pendant les croisades à tous les étrangers qui composaient les armées d'outre-mer, et ces étrangers s'accordèrent bientôt pour ne pas donner d'autre acceptation au mot roman que celle d'ouvrage d'imagination écrit en prose. Dante qui écrivait et qui parlait la langue de France, a constaté lui-même la signification du mot à la fin du $13^{\text {me }}$ siècle en disant ..." (Lacroix, Sciences et Lettres au Moyen Age. 2. ed. I877, S. 402). Andere haben gesagt, dafs man unter Romanen ursprünglich Erzählungen in Versen, dann solche in Prosa verstanden habe, so Pasquier in der schon citierten Stelle: “Tous ceux qui s'amusoient d'escrire les faicts heroïques de nos chevaliers, premierement en vers, puis en prose, appellerent leurs oeuvres romans." Schon die bisherige Geschichte des Wortes Roman macht es jedoch wahrscheinlich, dals es zunächst nicht im Begriffe desselben ausgedrückt lag, ob die so bezeichnete Erzählung in Versen oder in Prosa geschrieben war, dafs man vielmehr beide Arten von Erzählungen so nennen konnte. Und dies hat man auch wirklich gethan: Für die gereimten Erzählungen lassen die bisher im Verlaufe unserer Untersuchung angeführten Beispiele keinen Zweifel darüber bestehen, dals sie sich Romane nannten; ja, diese Benennung war ihnen so allgemein geläufig, dafs die abweichenden Fälle (abgesehen natürlich von einer Anzahl von Volksepen) eher als Ausnahmen anzusehen sind, wie z. B. der von W. Förster herausgegebene Chevaliers as Deus Espees, der sich durchweg Conte und nie Roman nennt. Besondere Hervorhebung aber verdient die Thatsache, dals die gereimten Erzählungen sich diese Bezeichnung bewahrten so lange es solche überhaupt gab, ja, der Kanzler Gerson wendet dieselbe noch ausschliesslich auf diese Dichtungén an, indem er sagt: "Ex lectione quorundam romanticorum, i. e. librorum compositorum in gallico poeticorum (bei Schmeller. Bayrisches Wörterbuch1 II 98 "Roman"). So sagt auch Coudrecte in seiner Anfang des 15. Jahrh. abgefassten Erzählung von der Melusine:

"Et si aucun demandoit comment

Voustre romant appelleray,

C'est le Romant de Parthenay.

Ainsi sire l'apelle len,

Ou le Romant de Lusignan.

Prenez le quel que vous vouldrez."

(H. Ward, Catal. of Rom. S. 696).

Und eine Stelle aus dem Jahre 1465 beweist das Gleiche: "Le Romant de Amys et Amille, fait et escript le 14 decembre, l'an 1465; et l'escript Henry Riet, boullengier, demeurant dे Aras."

1 2. Ausg. bearb. v. G. Karl Frommann. München 1877 . 


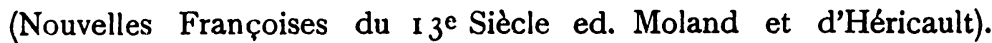
Dieser Roman ist ein Gedicht von 14000 Versen.

Was nun die Erzählungen in Prosa anlangt, so ist allerdings nicht zu verkennen, dass sich diejenigen der früheren Zeit mit Vorliebe die allgemeine Bezeichnung Conte, oder aber Histoire, Chronique zulegen. Ja, Ausdrücke wie "or dist li contes" sind gleichsam stehend für diese Werke geworden und die Bezeichnung Roman findet sich nur vereinzelt. Aber sie findet sich eben doch und beweist dadurch, dass man sie auch schon damals nicht auf die poetischen Erzählungen beschränkte. In den späteren Jahrhunderten, als die Prosawerke überhaupt zahlreicher wurden, mehren sich auch die Stellen wo solche Romane genannt werden, und das Wort beginnt also $\mathrm{zu}$ derjenigen modifizierten Bedeutung fort $\mathbf{z u}$ schreiten, die ihm noch heute eigentümlich ist und nach der man darunter ausschliesslich ein prosaisches Werk erzählenden Inhalts versteht. Die folgenden Beispiele mögen verdeutlichen, dals man von jeher und zu allen Zeiten diese Bezeichnung auf solche Werke angewendet hat.

Schon der französische Prosa-Tristan, den man gewöhnlich in das Ende des 12. Jahrh. setzt, und der uns in zahlreichen Handschriften aus dem I 3. Jahrh. erhalten ist, trägt den Titel (de Bure. Catalogue de la Vallière II 6I4): "Ci commence li Roumans du bon chevalier Tristan, filz au bon roy Melyadus de Loenois et de Sadoch." Weitere solche Beispiele sind: "Ci fine le Romans de Lancellot del Lac" (Handschrift aus dem I3. Jahrh. bei P. Paris. Mss. Fr. I 146). "Cis roumans fu parescris en l'an de l'incarnacion nostre Segnor mil deus cens et sixante et quatorze, le semedi apries les octaves de la Trinité." (Letzter Teil des Lancelot und Mort d'Artus. Ib. Il 36I-2). Auch Rusticien de Pise nennt seine Bearbeitung des Lancelot und des Tristan "Roman". (Ib. II 356). "Ci commence le Romanz des prophecies Merlin." "Ci finist le Romanz des prophecies Merlin." (Hucher, Le Saint Graal. I 279 u. 505. Handschrift vom Jahre I 30r). "Explicit don Roumans Lanselot et don Saint Greal et don Roumant de la mort au roi. Artu qui che dedans chest livre sont definit et accomplit outrement; et contient LXVIII coiiers et fu definis le lundi prochain devant le jour.de Paskes flories en marc, l'an mille CCCXLIIII." (P. Paris, Mss. Fr.I I 58). "Explicit le Roumant de Tristan et de Yseut qui fut fait l'an mille III .C. IIIIxx et XIX, la veille de Pasques grans" (d. h. den 17. April 1 400. Ib. II 343). "Et atant se tait le conte a parler d'eux car icy endroit fine le Romant du roy Cleriadus et de la royne Meliadice sa femme, et plus n'en parle pour le present." (Handschr. aus dem 15. Jahrh. bei H. Ward. a. a. O. S. 383-4). Der zwischen 1530 und 1540 gedruckte Roman von Johann von Paris, der eine freiere Prosaauflösung des altfranzösischen Jehan et Blonde ist (s. Oeuvres Poétiques de Beaumanoir, ed. H. Suchier I S. CXII), ist überschrieben: "S'ensuyt ung tresbeau et excellent ro- 
mant nommé Jehan de Paris, Roy de Franse." (Nisard, Histoire des Livres Populaires II 398).

Die Prosaauflösungen der späteren Jahrhunderte erstrecken sich übrigens nicht allein auf die höfischen Epen, denen ja die Bezeichnung Roman von Anfang an geläufig war, sondern auch, und zwar vor Allem, auf die alten Chansons de geste, und auch diese nannten sich Romane und gaben die ursprüngliche Bezeichnung Chanson auf. Jene Benennung nahmen sie um so leichter an, als sie nun selbstverständlich nicht mehr gesungen, sondern nur noch gelesen wurden. Auch die alten Volksepen selbst nannte man in der späteren Zeit allgemein Romane, denn auch bei ihnen konnte nunmehr von einem Singen nicht die Rede sein. So findet sich am Schlusse der Chanson des Saxons des Jean Bodel d'Arras in der Turiner Handschrift die folgende Angabe: "Datum anno Domini millesimo tricentesimo tricesimo primo, die Jovis post Assumptionem beate Marie Virginis, legit Colinus de Novionno, clericus abbatis Sancti Vitoni Virdunensis, totum istum romanum des Saines." (Blancandin et l'Orgueilleuse d'Amour ed. H. Michelant. S. 210). Wie schon bemerkt versteht man heute unter einem Roman nur noch eine Erzählung in Prosa. Diese Modifikation in der Bedeutung des Wortes vollzog sich allmählich und kann offenbar erst dann als abgeschlossen betrachtet werden, als es keine poetischen Erzählungen der Art mehr gab oder besser, als diese in Vergessenheit geraten waren. In jedem Falle ist dies aber, wie sich aus dem Vorhergesagten ergiebt, erst nach dem 15. Jahrh. eingetreten. Die Anfänge dieses Bedeutungswandels fallen aber jedenfalls schon in diese Zeit des Uebergewichtes der Prosa über die Poesie.

Ebenfalls nur annähernd läfst sich bestimmen, wann das Wort Roman zu seiner heutigen Bedeutung einer fingierten Erzählung kam, weil eben auch der Übergang zu dieser Bedeutung naturgemäls nur ein ganz allmählicher sein und dadurch bewirkt werden konnte, dafs eine lange Zeit hindurch Werke fingierten Inhalts sich so nannten. Unter den Werken, welche hier hauptsächlich in Betracht kommen sind zunächst zu nennen die Abenteuerromane, die, ganz die Schöpfung der Phantasie des Dichters, sich in einer durchaus unrealen Welt bewegten, ebenso auch die Prosaauflösungen nicht nur dieser, sondern auch der alten Chansons de geste. Zwar entbehrten ja die letzteren nicht des historischen Hintergrundes und die in ihnen geschilderten Ereignisse waren, wenn nicht historisch, doch während der Blütezeit der volkstümlichen Poesie durch die Tradition gleichsam geheiligt. Dies fiel nun weg, und weitere Veränderungen und Zuthaten trugen das Ihrige dazu bei, sie mit den andern fingierten Erzählungen auf die egleiche Stufe zu stellen. Es gehören ferner hierher die Prosaromane vom heiligen Graal mit ihren phantastischen Schilderungen, vor Allem aber endlich auch die allegorischen Dichtungen, der Roman von der Rose und seine zahlreichen Nachahmungen, die ja ihrem ganzen Wesen nach Fik- 
tionen waren und auf Realität keinen Anspruch machten. Im Widerspruch mit dieser Entwickelung scheint zu stehen, dass, wie wir gesehen haben, auch Geschichtswerke etc. sich mit Vorliebe Romane nannten. Dieser Widerspruch ist jedoch nur scheinbar, denn auch diese in der Vulgärsprache geschriebenen Geschichtswerke waren nicht immer frei von Fiktionen und poetischen $\mathrm{Zu}$ thaten, indem auch sie dem Geschmacke ihrer Lcser Rechnung trugen. Andererseits versäumen es auch die Verfasser der Abenteuerromane etc. nicht, durch häufige Berufungen auf fiktive Quellen ihren Dichtungen wenigstens den. Schein historischer Treue zu geben. Später gaben dann die Geschichtswerke etc. diese Bezeichnung gänzlich auf, eben weil man immer mehr den Begriff der Fiktion mit dem Worte verband. Diesen vom Standpunkt des Historikers verächtlichen Beigeschmack schsint das Wort bereits in der folgenden Stelle aus dem schon. S. 50 I: erwähnten Briefe König Johann's von : Böhmen zu haben, wo es heifst: "Ideo rogamus, quantum possumus, universos ut ... non credat narrationem ignorantium et romancii ..."

Verschiedene Anzeichen scheinen nun dafür zu sprechen, dafs das Wort schon im I3. Jahrh. zu dieser modifizierten Bedeutung hinneigte, was an sich nicht unwahrscheinlich ist, denn schon in jener Zeit war die Mehrzahl der so bezeichneten Werke fingierten Inhalts. Es kommen hier , hauptsächlich solche Stellen in Betracint, wo romanz und geste einander gegenübergestellt werden, welches letatere Wort gleichbedeutend gebraucht wurde mit Chronik, authentischem Bericht u. dgl. So heilst es im Roman de Renart (Supplément ed. Chabaille zu V. I 2 155):

"Je sai gestes et romans tous"

Und Baudouin de Condé (ed. Scheler II 93) erinnert an die tapferen Ritter der früheren Zeit mit den Worten:

"Si en fist on roumans et gestes

De quoi li renons ne faura,

Tant come li siecles durra."

Scheler bemerkt $\mathrm{zu}$ dieser Stelle: "Le ms. B a 'roumans de gestes' (historias de rebus gestis); jai préféré la distinction que présente mon ms. 'roumans (récits fictifs en langue vulgaire) et giestes' (récits historiques plus sévères)." Auch ich möchte mich dieser Ansicht anschliefsen, da mir kein weiteres Beispiel der Verbindung "romanz de geste" bekannt ist. Schwieriger ist die Entscheidung darüber, ob romanz hier wirklich schon die Bedeutung von fingierter Erzählung hat; sicher beweisend für dieselbe sind die beiden angeführten Stellen nicht. In neuerer Zeit haben Literarhistoriker den Ausdruck "Roman de geste" auf die Volksepen des Mittelalters angewendet; so nennt Kreyssig (Gesch. der franz. Nationalliterat. 5. Aufl. S. 26) z. B. das Rolandslied einen "Roman de geste". Ich halte eine derartige Bezeichnung für unberechtigt, da Roman den Begriff einer gesagten Erzählung in sich schlielst, ganz 
abgesehen davon, dafs diese Verbindung überhaupt nicht weiter belegt ist. Man trägt durch eine solche Bezeichnung etwas Fremdartiges in diese Dichtungen hinein und thäte besser, für die volkstümlichen Epen die treffende Benennung "Chansons de geste" ausschliefslich beizubehalten.

Die folgende Stelle scheint etwas deutlicher für die obige Bedeutung des Wortes im I3. Jahrh. zu sprechen:

"Celles et cil soient confondu

Qui croient un roman qui fu,

Qui dist que de flour iert venue

Sainte Anne et engenue."

(Hist. Litt. de la Fr. XVIII 837).

Bereits zu dieser Zeit also scheint man mit Vorliebe das Wort auf fingierte Erzählungen und zwar mit Bewufstsein angewendet zu haben. Um so mehr gilt dies von den folgenden Jahrhunderten, wo die Geschichtswerke diese Bezeichnung fallen liefsen und dieselbe immer ausschliefslicher auf Erzählungen fingierten Inhalts angewendet wurde. Um noch einige spätere Belege anzuführen, so sagt der Kanzler Gerson in der schon zum Teil (S. 5 I 2) citierten Stelle: "Ex lectione quorumdam romanticorum, i. e. librorum compositorum in gallico poeticorum de gestis militaribus in quibus maxima pars fabulosa est." Und bei Fauchet a. a. O. S. 544 heilst es: "Les Italiens, Espagnols, Alemans et autres ont esté constraints forger leur romans et contes fableux sur les telles quelles inventions de nos trouverres." Spätere Schriftsteller gebrauchen daher auch das Wort in übertragenem Sinne, um die Nichtexistenz oder Unwahrheit einer Sache auszudrücken. So z. B. Molière in Le Malade Imaginaire Akt 3, Scene 3: "Lorsqu'un médecin vous parle d'aider, de secourir, de soulager la nature, de lui ôter ce qui lui nuit et lui donner ce qui lui manque, de la rétablir et de la remettre dans une pleine facilité de ses fonctions; lorsqu'il vous parle de rectifier le sang, de tempérer les entrailles et le cerveau, de dégonfler la rate....; il vous dit justement le roman de la médecine. Mais quand vous en venez d̀ la vérité et à l'expérience, vous ne trouvez rien de tout cela; et il en est comme de ces beaux songes qui ne vous laissent au réveil que le déplaisir de les avoir crus." Und Voltaire sagt in seinem Traité de Métaphysique: "Ceux qui ont fait le roman des idées se sont flattés qu'ils rendraient raison des idées de l'infini."

In einem gewissen Widerspruch damit scheint zu stehen, dals wir z. B. noch um das Jahr 1500 den Ausdruck "vrai roman" finden:

"Icy ce commence l'histoire

Et vray rommant ample et notoire

Du riche et puissant duc Lyon

Qui vertus eut un million, 
Le quel fu fils comme il appert

Du duc de Bourges tres expert."

(P. Paris, Mss. Fr. III 4).

Dieser Widerspruch ist jedoch nur scheinbar. Die Thatsache dafs hauptsächlich fingierte Erzählungen Romane genannt wurden, bleibt bestehen, nur kam sie den einzelnen Individuen, und wohl auch den verschiedenen Epochen, nicht in gleich deutlicher. Weise zum Bewurstsein.

Aber nicht einfach eine fingierte Erzählung versteht man unter einem Roman, sondern vor Allem eine solche, deren Inhalt besteht aus ungewöhnlichen, die Vorkommnisse des alltäglichen Lebens an Bedeutung überragenden Ereignissen und Zuständen, womit jedoch keineswegs gesagt sein soll, dafs diese selbst unwahrscheinlich sind. Beide Bedeutungen des Wortes sind augenscheinlich nahe verwandt und greifen daher zuweilen in einander über, so jedoch, dals bald die eine, bald die andere mehr zum Ausdruck kommt. Dies tritt besonders an solchen Stellen hervor, wo "roman" und "histoire" einander gegenübergestellt werden, und in denen also "roman" bald das Erdichtete im Gegensatz zu dem wirklich Geschehenen, bald das Aufsergewöhnliche im Gegensatz zu dem Gewöhnlichen bezeichnet. Für den ersteren Fall möge als ein Beispiel für viele die folgende Stelle aus Bossuet dienen (bei Littré, Dict. de la L. Fr. "Roman" 2,20): "Elle y perdait (dans l'étude de l'histoire) le goût des romans et de leurs fades héros; et soigneuse de se former sur le vrai, elle méprisait ces froides et dangereuses fictions." Für den zweiten Fall bilden die Worte Huet's am Schlusse seiner Abhandlung "De l'Origine des Romans" einen treffenden Beleg. "Je souhaiterois", sagt er dort, "pour l'interest que je prens à la gloire du grand roy que le ciel a mis sur nos testes, que nous eussions l'histoire de son regne merveilleux écrite d'un stile aussi noble, et avec autant d'exactitude et de discernement. La vertu qui conduit ses belles actions est si heroïque, et la fortune qui les accompagne est si surprenante, que la postérité douteroit si ce seroit une histoire ou un roman." In dieser letzteren Bedeutung hat man jedenfalls auch das Wort Roman zu fassen an der schon S. 50 I citierten Stelle aus Brantôme, wo dieser die Histoire du chevalier Bayard einen Roman nennt, womit er nur hinweisen will auf das Aufserordentliche der von diesem Helden vollbrachten Thaten. Dagegen ist hier nicht an die Bedeutung des Wortes von erdichteter Erzählung zu denken. Dasselbe gilt in manchen Fällen auch heute. "Dans la conversation", sagt Littré (s. conte), "quand après un récit entendu on dit: c'est un roman, on veut dire que les aventures racontées sont extraordinaires; elles peuvent néanmoins être vraies."

Dafs das Wort übrigens schon in den früheren Jahrhunderten diese Bedeutung angenommen hatte, versteht sich in Anbetracht 
des Inhalts der so bezeichneten Werke von selbst; ja sie tritt naturgemäfs in dieser früheren Zeit noch mehr hervor als hentzutage:

"De quoy cils Menestriers font les nobles romans"

heifst es in der Chronique de Bertrand du Guesclin (bei Du Cange "Ministelli"), und Oresme (Eth. 27) sagt: "Tragédies sont dites comme romans qui parlent et traitent de aucuns grans faiz notables."

Je nach der Geschmacksrichtung der Zeit und dem durch sie bedingten Inhalt der sogenannten Romane änderte sich natürlich auch die Bedeutung des Wortes. Im Mittelalter und weit bis in die neue Zeit hinein verstand man darunter hauptsächlich Rittergeschichten, die ja nicht nur während der Blütezeit des Ritterwesens in Aufnahme waren, sondern auch nach dem Verfall desselben den Hauptbestandteil der mittelalterlichen erzählenden Litteratur gebildet haben und bekanntlich noch zur Zeit Franz' I. in den Amadisromanen eine künstliche Wiederbelebung erfuhren. Eben weger der in ihnen geschilderten Festlichkeiten, Turniere, Kriegszüge und Abenteuer nannte man sie "nobles romans". So sagt ja auch Gerson von den Romanen an der schon mehrfach citier. ten Stelle, dafs sie handeln "de gestis militaribus", und eine andere Stelle, aus dem I6. Jahrhundert (angeführt bei Littré "Roman") besagt das Gleiche: "Et acheverent tant nobles faiz, et prindrent citez, villes et chasteaulx assis sur roches, que de leur vie peust on faire romans." Hierher sind auch zu ziehen die S. 501 gegebenen Notizen über Joinville, Froissart, Brantôme etc., sowie die S. 485 erwähnten Ableitungsversuche des Wortes Roman.

Fs dauerte also lange, bis man diesen den Sitten der Zeit schon lange nicht mehr entsprechenden Geschmack autgab und die "Romane" auf eine natürlichere Basis stellte, in Folge dessen die Zahl der behandelten Stoffe sich vergröfserte und die Bedeutung des Wortes eine weitere und umfassendere wurde.

Die Liebe hat von jeher in den "Romanen" eine grofse Rolle gespielt. Schon in den höfischen Epen des 12. und 13. Jahrh. und den ihnen nachfolgenden Prosaromanen führen die Ritter Kämpfe um Frauenliebe und Frauengunst, und der Besitz der Geliebten bildet gewöhnlich den Lohn ihrer Thaten und den Schlufs der Erzählung. Und dieses Thema ist auch in der Folgezeit nie von den Romanschreibern unbenutzt gelassen worden, nur tritt es in den einzelnen Epochen in verschiedenem Grade hervor. Huet (De l'Orig. des Romans S. 2) konnte daher zur Zeit der Mlle de Scudéry sagen: "Ce que l'on appelle (aujourd'huy) proprement romans sont des histoires feintes d'aventures amoureuses, écrites en prose."

In keiner Gattung ist übrigens wohl so viel Schlechtes zu Tage gefördert worden als im Romane, daher man denn zuweilen dem Wort einen verächtlichen Beigeschmack gegeben hat. So erklären sich Stellen wie die folgende: "De quel étonnement 
n'auroit pas été frappé Romulus, si on lui avoit dit que la célèbre ville qu'il fondoit, donneroit naissance au mot françois roman, qui sert à exprimer et désigner ce qu'il y a de plus futile dans notre littérature?" (Barb. Méon, Fabl. et Contes I 22).

Was die heutige Bedeutung des Wortes Roman anlangt, sofern es in Gegensatz tritt zu anderen erzählenden Dichtungsgattungen, so sei es erlaubt die Worte Littrés (a. a. O. "Conte") anzuführen,: "Il n'y a pas de différence fondamentale entre le conte le roman; l'un et l'autre sont des narrations mensongères ou regardées comme telles. Tout ce qu'on peut dire, c'est que conte est le terme générique puisqu'il s'applique à toutes les narrations fictives depuis les plus courtes jusqu'aux plus longues. Le roman ne se dit que de celles-ci. Un conte de trois pages ne s'appellera jamais un roman, tandis qu'un roman est, dans toute la rigueur du terme, un conte suffisamment long. La nouvelle ne se distingue non plus au fond du conte ou du roman. Dans l'usage ordinaire c'est un roman de petite dimension dont le sujet est présenté comme nouveau ou peu ancien, ou avec des détails inconnus jusqu'ici." Auch im Mittelalter bezeichnete man, wie heute, mit conte zunächst eine Erzählung ganz im Allgemeinen, daneben scheint man jedoch das Wort mit Vorliebe auf kleinere Erzählungen angewendet zu haben, deren Stoffe meist dem bürgerlichen Leben entnommen waren oder doch die bürgerlichen Kreise vorzugsweise interessierten. Besonders gern werden daher die Contes mit den ihnen verwandten Fablels und Dits zusammengestellt (s. S. 507). Zuweilen wird es auch besonders betont, dals die in den Contes behandelten Stoffe von untergeordneter Bedeutung sind:

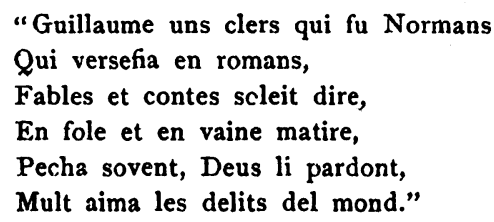

Auch im Mittelalter gebrauchte man das Wort Roman meist, wie jetzt ausschliefslich, zur Bezeichnung umfangreicherer Werke. Dafs man aber früher auch kürzere Werke so nannte, beweisen z. B. der "Romanz de un chivaler e de sa dame e de un clerk" (Romania I 73 ff.), oder der satirische "Romanz des Franceis" (Jubinal, Nouv. Rec. II I) und viele andere.

Eine ähnliche Entwickelung wie das Wort romanz machte auch das von ihm abgeleitete Verbum enromancer oder romancer durch. Ursprünglich bedeutet es "in romanische Sprache übersetzen", z. B.:

Nuls homs qui n'a engin divin,

$\mathrm{Ne}$ puet comprendre le latin, 
Dont encore se doit moins fier

De tel latin romancier."

(Du Cange, "Romanus").

Entsprechend der Verwendung des altfranzösischen "en romanz" im Sinne von "deutlich, klar" (s. S. 49 I f.), ist man geneigt, auch das Verbum zuweilen in übertragenem Sinne mit "verdeutlichen" oder dgl. zu übersetzen (vgl. unser "verdeutschen"), so an der folgenden Stelle im Roman de la Rose (ed. Fr. Michel V. 208I ff.):

\section{"Por quoi il voille tant atendre \\ Que g'espoigne et que g'enromance \\ Du songe la senefiance."}

In späteren Jahrhunderten bedeutet romancer dann: "in einen einen Roman bringen", so wenn Sainte Beuve sagt: "D'Urfé, comme presque tous les romanciers, avait mis dans son roman les personnages de sa connaissance, et s'y était mis lui-même et les aventures de sa jeunesse; mais tout cela était combiné, déguisé et romancé de telle sorte que lui seul pouvait servir de guide dans ce labyrinthe." (bei Littré, "Romancer").

Aufser "romanz" begegnen im Altfranzösischen noch die Formen "roman" und "romant". Die Form mit t erklärt sich daraus, dafs man. das stammhafte $s$ des Nominativs für ein Flexionszeichen ansah und einen Accusativ romant bildete. Dieselbe erfuhr dann Weiterbildungen wie romantique, romantiser, romantisme. Dieses $t$ erscheint zuerst, durch den Reim bezeugt, in der 2. Hälfte des 1 2. Jahrhunderts. In der zwischen 1 I 76 und I I 8 I verfafsten Übersetzung des hohen Liedes von Landri de Waben (s. Suchier, Zu den altfrz. Bibelübersetzungen, in der Ztschr. f. rom. Phil. VIII 4I 4) heifst es:

\section{"Mais tant requiers que cest romant Unkes ne viegne en main d'enfant."}

(Hist. Litt. de la Fr. XV 483).

Es mögen noch einige der älteren Beispiele folgen, späterhin begegnet diese Form häufig.

"Son fils ot non Hugon de Saint Gille le grant,

Sire de Valvenise, la seignorie tenant, Qui avec Godeffroy alla la mer passant,

Ainsi qu'avés oy recorder ou romant."

(Parise la Duchesse ed. Guessard et Larchey. S· XII).

"Et car laissiés aler dame Hersant

Dessi al chevalier a son talant:

Ele li dira ja de' son romant."

(Aiol et Mirabel, ed. W. Förster. V. $2684 \mathrm{ff}$.).

Aus dem Französischen ist dann das Wort Roman in der modifizierten Bedeutung nicht nur in andere Sprachen, wie in das 
Italienische übergegangen, sondern auch andere Sprachfamilien haben dasselbe in ihren Wortschatz aufgenommen. Schon früh finden wir es im Englischen in der Form "romans" oder "romance". Zunächst bezeichnete man damit die französschen Originale, von denen Übersetzungen und Nachahmungen in englischen Gedichten existierten (vgl. Warton, History of English Poetry, ed. Price I 62 Anm.). Später jedoch gebrauchte man es auch in der Bedeutung, welche es im Französischen angenommen hatte, nämlich in der von fingierter Erzählung, hauptsächlich jedoch zur Bezeichnung epischer Gedichte. Eine Nebenform ist "romaunt", entsprechend altfranzösischem "romant". Sie findet sich bereits in der Chaucer zugeschriebenen Übersetzung des Romans von der Rose, und noch Byron nennt seinen Childe Harold einen Romaunt. Was von der Vortragsweise der französischen Romanz gilt, scheint in ähnlicher Weise auch auf diejenigen der mittelenglischen Romances Anwendung zu finden, d. h. sie wurden während der Herrschaft der höfischen Kunst mehr gesagt als gesungen. Nach dem Verfall des Rittertums jedoch in England und Schottland scheinen sie auch wieder in einer volksmälsigeren Weise vorgetragen, $d . h$. gesagt und gesungen oder doch unter Instrumentalbegleitung recitiert worden $\mathrm{zu}$ sein. (Vgl. hierüber Ferd. Wolf, Über die Lais. S. $260 \mathrm{ff.}$.).

Ins Deutsche ging das Wort im 17. Jahrh. über in der Form "Roman". Daneben findet sich auch "Romain", eine Form, die auch im Altfranzösischen begegnet. Merkwürdig ist dagegen das Femininum "die Romaine", für welches Scherer (Strafsburger Quellen und Forschungen XXI 6) Belege giebt. Ja, man findet in demselben Werke den Singular "der Romain", und "der Roman" neben dem Plural "die Romanen". Scherer a. a. O. deutet an, dafs dieses Femininum vielleicht auf Mifsverständnis oder Halbkenntnis des Französischen beruhen könne, etwa unter Einwirkung des lateinischen fábula romanensis.

Im Spanischen hat sich das Wort in dieser Bedeutung nicht erhalten und man versteht dort unter Romances jene volkstümlichen lyrisch-epischen und gesungenen Gedichte, die nicht älter sind, als das 14. Jahrhundert (die meisten gehören dem 15. Jahrhundert an), und die, wie Milá (De la Poesia Castell. Heroica Popular) bewiesen, Trümmer sind eines Volksepos aus dem 12. und 13. Jahrhundert. Diese Bezeichnung ist jedoch erst später ausschliefslich auf diese Gattung angewendet worden, die älteren Romanzen nannten sich gewöhnlich Cantares. Die älteste Stelle, wo romance unzweifelhaft in diesem Sinne $z \mathrm{u}$ verstehen ist, findet sich nach Ferd. Wolf (Über die Romanzenpoesie der Spanier; in den Wiener Jahrb. der Literat. CXVII 82 ff.) in einem Briefe des Marquis von Santillana, wo es heilst: "Infimos son aquellos que sin ningunt orden, regla ni cuento, facen estos romances i cantares, de que la gente baja é de servil condicion se alegra." Um das frühere Vorkommen des Wortes in dieser Bedeutung $\mathrm{zu}$ beweisen, hat man darauf hingewiesen, dafs nach der Einnahme von Sevilla i. J. 1248 durch den 
heil. Ferdinand Ländereien an zwei Dichter "Nicolas de los Romances" und "Domingo de los Romances" gegeben wurden. Die Bedeutung des Wortes an dieser Stelle ist jedoch zweifelhaft und ein Schlufs aus ihr nicht zu ziehen. Dem wahren Sachverhalte widerspricht es ferner, wenn Ticknor (Geschichte der schönen Literatur in Spanien. Deutsch von Julius. I 97) äufsert: "Dafs solche Romanzen bereits in den frühesten Zeiten vorhanden waren, kann schon ihr blofser Name (Romances) andeuten. Denn dieser scheint mit dem Begriffe verbunden, dals sie in jener Zeit die einzige bekannte Art von Gedichten in der romanischen Sprache abgaben, und ein solcher Zeitraum kann nur derjenige gewesen sein, welcher unmittelbar auf die Bildung der Sprache selbst gefolgt ist.“

Die spanischen Romanzen heben übrigens sehr selten ihre Vortragsweise hervor. Die folgende Stelle ist das einzige Wolf bekannte Beispiel, in welchem es besonders ausgesprochen wird, dafs das Gedicht eine Romanze und zum Singen bestimmt ist, und wo zugleich der Name des Dichters genannt wird:
"Que este romance se fizo,
Se hizo para cantar;
El cual fué hecho y trobado
Por Fernando de Villareal."

(Ferd. Wolf, Über eine Sammlung spanischer Romanzen in fliegenden Blättern. S. 95).

Aus Spanien ist nun das Wort romance (wo es übrigens masc. ist) zur Bezeichnung einer besonderen Gattung von Gedichten auch in andere Länder übergegangen, jedoch verbindet man nicht überall den gleichen Begriff mit dem Worte. Im Französischen bedeutet es jetzt eine rein lyrische Gattung von Liebesliedern. In der altfranzösischen Litteratur finden sich allerdings den spanischen Romanzen vollkommen entsprechende Lieder, diese nennen sich jedoch nicht Romances, sondern Chansons. Erst in neuerer Zeit hat man diese Bezeichnung von ihnen gebraucht. So scheidet P. Paris (Romancero François S. 3) die Poesien des Audefroy le Bastard in "chansons et romances amoureuses" und versteht unter den ersteren diejenigen, welche die Liebe des Dichters selbst zum Gegenstande haben, unter den letzteren aber "le récit d'anciennes aventures amoureuses et chevaleresques." Auch im Provenzalischen finden wir Romanzen, jedoch ebenfalls nicht unter diesem Namen. Wilhelm IX. Graf von Poitiers nennt z. B. eine von ihm gedichtete Romanze (P. Heyse, Rom. Inedita S. 9) "Vers".

Die entsprechenden Volkslieder der Engländer führen den Namen Ballads. Diese Bezeichnung (ursprünglich im Italienischen und Provenzalischen ein Tanzlied bedeutend) gelangte dann mit der Percyschen Sammlung auch nach Deutschland; zwar kommt das Wort Ballade schon einige Male früher in Deutschland vor, aber mit zweifelhafter Bedeutung. Ungefähr um dieselbe Zeit wurde auch die spanische Bezeichnung nach Deutschland gebracht durch 
Gleim, der hier zuerst diese Gattung kunstmäfsiger behandelte und sich in seinen "Romanzen" besonders den Spanier Gongora ( $\dagger$ 1627) und den Franzosen Moncrif ( 1 1770) zu Mustern nahm. So haben wir also im Deutschen zwei Bezeichnungen für im Grunde dieselbe Sache, so jedoch dafs die "Ballade" die Ereignisse mehr in dem düsteren Kolorit des nordischen Volksliedes darstellt, die "Romanze" dagegen das hellere Gewand jener episch-lyrischen Gedichte des Südens trägt. Die Dichter selbst gebrauchen übrigens beide Bezeichnungen ziemlich unterschiedslos, jedoch gewinnt der Name Ballade, nachdem er einmal in Deutschland eingeführt ist, die Oberhand. Auch in der Musik haben wir Romanzen und Balladen, jedoch falıen diese beiden Begriffe mit den poetischen nicht ganz zusammen. Unter der Romanze versteht man musikalisch in der Regel ein strophisch komponiertes Singstück in einer einfachen Melodie; die Ballade dagegen versucht, vollständig durchkomponiert, die Momente der Dichtung in grölseren selbständigen Tonbildern wiederzugeben. In jener kehrt auch der Refrain des Volksliedes in entsprechenden Tonwiederholungen und in einem öfters vorgeschobenem Ritornell wieder, in dieser ist er zum Leitmotiv verarbeitet. (Vgl. zu diesen Ausführungen Holzhausen, Ballade und Romanze, Dissert. Halle I 882 . S. I-9).

Fassen wir die Hauptpunkte unserer Untersuchung in kurze Worte zusammen, so ergiebt sich das Folgende:

"Romanisch" nannten sich mit Ausnahme des Italienischen alle diejenigen Sprachen, die eine Fortentwickelung sind der durch lokale Verhältnisse modifizierten römischen Volkssprache. Schon in früher Zeit, bevor es zu einer schriftlichen Fixierung derselben kam, traten diese Sprachen der grofsen Masse des Volkes in einen bewulsten Gegensatz zum Lateinischen, als der Sprache der Gesetzgebung, Kirche und Wissenschaft. In den beiden Sprachen Frankreichs scheint die Bedeutung des Wortes insofern zu differieren, als man im Norden dasselbe nicht nur auf das ganze Gebiet der Langue d'oïl, sondern bald speziell auch auf die für besonders rein gehaltene Sprache des Herzogstums Francien anwendete. Während nun die anderen romanischen Sprachen diese Bezeichnung bis auf den heutigen Tag bewahrten, gaben die beiden letztgenannten dieselbe am Ausgange des Mittelalters auf und nannten sich von da $a b$ ausschliefslich français und prouvençau. Im Französischen gewinnt diese Bezeichnung bereits im 14. Jahrhundert die Oberhand, um dann im Laufe des I5. Jahrhunderts die allein herrschende zu werden, sodals man im 16 . Jahrhundert bereits von einem roman antique im Gegensatz $\mathrm{zu}$ dem français moderne sprechen konnte.

Eine Wirkung des Gegensatzes zwischen Romanisch und Lateinisch war die Anwendung des Wortes Roman auf ein in der Vulgärsprache geschriebenes Werk. Den ersten Anstors dazu gaben um die Mitte des 12. Jahrh. die Übersetzungen aus dem Lateini- 
schen und noch in der 1. Hälfte des 15. Jahrh. finden wir solche Übersetzungen in dieser Weise benannt. Nachdem so ein Mal der Anstofs gegeben war blieb es nun nicht aus, dafs auch andere. nicht auf lateinischen Texten beruhende, in der Volkssprache abgefarste Werke die gleiche Bezeichnung wählten. In dieser allgemeinen Bedeutung von "Werk in romanischer Sprache" finden wir das Wort besonders häufig im Provenzalischen angewendet, während es im Französischen daneben bald zu der Bedeutung von "Erzählung" fortschreitet, indem die zuerst sogenannten Romane fast ausschliefslich der erzählenden Litteratur angehörten und durch ihre weite Verbreitung grofsen Einflufs auf ihre Zeit ausübten. Dieser Bedeutungswandel vollzieht sich im Wesentlichen in der zweiten Hälfte des I 2. Jahrhunderts und steht Anfang des I3. Jahrhunderts fest. Auch Geschichtswerke, Chroniken etc. legten sich mit Vorliebe diese Benennung zu.

Sehr bald trat eine weitere Modifikation der Bedeutung des Wortes ein, indem man darunter eine zum Sagen oder Lesen, nicht aber zum Singen bestimmte Geschichte verstand, und zwar nicht nur im Französischen, sondern auch im Provenzalischen und Spanischen.

Romane hiefsen sowohl die Erzählungen in Versen als diejenigen in Prosa. Zur Zeit des Übergewichtes der ersteren verstand man jedoch hauptsächlich diese darunter und sie bewahren sich auch diese Bezeichnung bis zu den spätesten Zeiten ihres Bestehens. Mit dem Überhandnehmen der Prosa und dem allmählichen Erlöschen der Epik tritt dann ein Umschwung ein, der mit der ausschliefslichen Anwendung des Wortes auf prosaische Erzählungen endet. Als ein vollzogener ist jedoch dieser Wandel erst nach dem i 5. Jahrh. anzusehen.

$\mathrm{Da}$ die meisten der sogenannten Romane erdichteten Inhalts waren, so verband man schon früh den Begriff der Fiktion mit dem Worte. Anzeichen dafür finden sich schon im I3. Jahrhundert und in den folgenden Jahrhunderten fixiert sich diese Bedeutung mehr und mehr, daher denn auch die Geschichtswerke diese ihre ehemalige Bezeichnung aufgeben. Es liegt ferner in dem Begriff des Wortes Roman, dafs die in diesen Werken geschilderten Erẹignisse und Zustände die Vorkommnisse des alltäglichen Lebens an Bedeutung überragen; dies tritt namentlich in den früheren Jahrhunderten hervor.

Im Mittelalter und weit bis in die neue Zeit hinein verstand man unter Romanen hauptsächlich Rittergeschichten; erst spät erweiterte sich die Bedeutung des Wortes mit der zunehmenden Zahl der behandelten Stoffe.

Die Liebe, ein stets von den Romandichtern ausgebeutetes Thema, tritt zuweilen derartig in den Vordergrund des Interesses, dafs sie das ganze Werk beherrscht und somit auch die Bedeutung des Wortes Roman modifiziert. 
Aus dem vielen Schlechten, das in dieser Gattung zu Tage gefördert worden ist, erklärt sich der verächtliche Beigeschmack, den man zuweilen dem Worte gegeben. Erst in späterer Zeit beschränkte man die Anwendung des Wortes ausschliefslich auf Werke von gröfserem Umfange, doch war dies auch in den früheren Jahrhunderten das Gewöhnliche.

Aus dem Franz. ging dann das Wort in andere Sprachen über, wie in das Italienische, Englische, Deutsche. Im Spanischen hat es sich in dieser Bedeutung nicht erhalten; hier bezeichnet man mit Romances (sicher bezeugt erst im 15. Jahrh.) eine bestimmte Gattung lyrisch-epischer Gedichte. Auch dieses Wort hat von seiner Heimat aus die Wanderung in andere Länder angetreten.

P. VOELKER. 